\title{
A Multi-scale Approach for the Discovery of Zeolites for Hydrogen Sulfide Removal
}

\author{
Tingting Liu ${ }^{c}$, Eric L. First ${ }^{c}$, M. M. Faruque Hasan ${ }^{a, b}$, and Christodoulos A. Floudas ${ }^{a, b, *}$ \\ ${ }^{a}$ Artie McFerrin Department of Chemical Engineering, Texas A\&M University \\ College Station, TX 77843, USA. \\ ${ }^{b}$ Texas A\&M Energy Institute, Texas A\&M University \\ College Station, TX 77843, USA. \\ ${ }^{c}$ Department of Chemical and Biological Engineering, Princeton University \\ Princeton, NJ 08544, USA.
}

\begin{abstract}
Removing $\mathrm{H}_{2} \mathrm{~S}$ from industrial gases is important to avoid operational hazards and to meet environmental regulation. Microporous zeolites are potential adsorbents for separating $\mathrm{H}_{2} \mathrm{~S}$ from other gases. While large number of candidate zeolites exists, it is not trivial to select costeffective zeolites capable of satisfying process constraints and specifications. In this work, a novel method for the zeolite-based $\mathrm{H}_{2} \mathrm{~S}$ separation is put forward which pertains to a multiscale modeling, simulation, and optimization framework for combined material screening and process optimization to reduce the overall process cost. The framework spans the atomistic and mesoscopic scales for the screening and selection of zeolites and the macroscopic scale for the simulation and selection of optimal conditions for pressure swing adsorption (PSA)-based $\mathrm{H}_{2} \mathrm{~S}$ separation technology. Applying this framework, several novel zeolites have been identified for the first time for separation of $\mathrm{H}_{2} \mathrm{~S}$ from representative $\mathrm{H}_{2} \mathrm{~S} / \mathrm{CO}_{2}, \mathrm{H}_{2} \mathrm{~S} / \mathrm{N}_{2}$, and $\mathrm{H}_{2} \mathrm{~S} / \mathrm{CH}_{4}$ mixtures. The zeolites which are screened are capable of removing $\mathrm{H}_{2} \mathrm{~S}$ from natural gas, acid gas, tail gas, flue gas, refinery gas, biogas, landfill gas, and other gases of industrial importance. Results show that it is possible to perform cost-effective $\mathrm{H}_{2} \mathrm{~S}$ removal by exploiting reverse selectivity of the gas molecules using novel micro-porous materials. We have also identified zeolite $\mathrm{ABW}$ as an adsorbent with high potential for commercialization for multi-purpose gas separation including acid gas removal from natural gas and carbon capture from power plants.
\end{abstract}

\footnotetext{
*Author to whom all correspondence should be addressed; Tel: (979) 458-0253; E-mail: floudas@tamu.edu.
} 


\section{Introduction}

$\mathrm{H}_{2} \mathrm{~S}$ is a toxic, odorous and corrosive gas found in many fuels and chemicals including natural gas, refinery gas, tail gas, biogas, landfill gas, synthesis gas and coke-oven gas. It is often produced from industrial activities such as petroleum refining, natural gas processing, power generation, coal gasification, pulp and paper manufacturing, food processing, wastewater treatment and semiconductor manufacturing. More than $14 \%$ of the U.S. natural gas reserves are contaminated by unacceptable levels of $\mathrm{H}_{2} \mathrm{~S}$ (Dalrymple, Trofe, and Leppin, May 23, 1994), which broadly range from 4 ppm - 42.5 mole \% (Alexander and Winnick, 1994), but can be as high as 90\% (T-Raissi, 2002). Examples of "ultra-sour" gas reserves include the Cotton Valley pinnacle reef in East Texas of U.S. (87\% $\left.\mathrm{H}_{2} \mathrm{~S}\right)$, Zhaolanzhuang in China $\left(60-90 \% \mathrm{H}_{2} \mathrm{~S}\right)$, and Caroline and Bearberry gas field in Alberta, Canada $\left(70-90 \% \mathrm{H}_{2} \mathrm{~S}\right) . \mathrm{H}_{2} \mathrm{~S}$ is also present in coal and other petroleum-based fuel gases, and is a major air pollutant from chemical and power plants.

$\mathrm{H}_{2} \mathrm{~S}$ must be removed or reduced to a permissible level from gaseous fuels before they can be transported or used. The presence of $\mathrm{H}_{2} \mathrm{~S}$ leads to pipeline corrosion during natural gas transportation. It is also considered as a serious corrosive contaminant for fuel processing during coal gasification and diesel reforming (Burke, Winnick, Xia, and Liu, 2002).

Several technologies are available for $\mathrm{H}_{2} \mathrm{~S}$ removal, including absorption, membrane separator, catalytic oxidation, catalytic membrane contactor, and microbial treatment (Stewart and Arnold, 2011; Kidnay, Parrish, and McCartney, 2011; Towler, Shethna, Cole, and Hajdik, 1997; Cnop, Dortmundt, and Schott, 2007; Syed, Soreanu, Falletta, and Béland, 2006). Industrial processes to remove $\mathrm{H}_{2} \mathrm{~S}$ typically employ absorption to separate concentrated $\mathrm{H}_{2} \mathrm{~S}$, followed by Claus treatment to convert to elemental sulfur. However, these processes are highly energy intensive, and can be as extensive and complicated as the rest of the processes (Nowacki, 1994). While alkanolamine absorption processes are widely deployed to reduce acid gas contents to about 10 ppm (Towler, Shethna, Cole, and Hajdik, 1997), high energy consumption and cost of solvent regeneration and solvent degradation are major challenges which still need attention. Bioprocesses involving microorganisms for the bioxidation of $\mathrm{H}_{2} \mathrm{~S}$ are suitable mostly for the $\mathrm{H}_{2} \mathrm{~S}$ removal from biogas (Syed, Soreanu, Falletta, and Béland, 2006).

Adsorption-based gas separation (Ruthven, 1984; Yang, 1987) provides promising alternatives 
for gas sweetening and $\mathrm{H}_{2} \mathrm{~S}$ separation applications. Adsorption offers multiple operational modes such as pressure-swing adsorption (PSA), vacuum-swing adsorption (VSA), and temperatureswing adsorption (TSA). Many PSA processes have been studied in the literature (Ruthven, Farooq, and Knaebel, 1994; Agarwal, Biegler, and Zitney, 2010; Hasan, First, and Floudas, 2013; Reynolds, Ebner, and Ritter, 2006; Ho, Allinson, and Wiley, 2008; Webley and He, 2000). PSA, which involves passing a gas mixture through a column packed with a microporous adsorbent that selectively adheres one gas over others, has been shown to be cost-effective for many important gas separations including carbon capture (Hasan, First, and Floudas, 2013; Hasan, Baliban, Elia, and Floudas, 2012b; Hasan, Boukouvala, First, and Floudas, 2014; Hasan, First, Boukouvala, and Floudas, 2015) and natural gas purification (First, Hasan, and Floudas, 2014).

Hasan et al. (Hasan, Baliban, Elia, and Floudas, 2012a,b) optimized different separation processes including absorption, membrane, and adsorption for $\mathrm{CO}_{2}$ separation from flue gases, and showed that a single material is not always the best for all feed compositions and flow rates. In fact, the cost of a PSA process significantly varies depending on the material selected for separation. To this end, microporous zeolites have large internal surfaces for adsorption, and can significantly reduce the energy consumption and cost of a PSA-based gas separation. More than 200 zeolites have been found or synthesized and numerous hypothetical zeolite frameworks can be considered. However, it is a challenge to simultaneously find the optimal zeolite and PSA process for $\mathrm{H}_{2} \mathrm{~S}$ removal. The existence of large number of alternative materials and different operating conditions make the design and optimization of PSA process very challenging. An efficient computational framework is therefore required to screen for the most promising candidates.

Previously, we introduced a computational framework that effectively combines material selection and process optimization to efficiently screen large databases of microporous materials (Hasan, First, and Floudas, 2013; First, Hasan, and Floudas, 2014). In this work, a novel method for the adsorption-based $\mathrm{H}_{2} \mathrm{~S}$ separation is put forward which pertains to a multi-scale modeling, simulation, and optimization framework for combined material screening and process optimization to reduce the overall separation cost. The framework spans the atomistic scale and the mesoscopic scale for the screening and selection of zeolites and the macroscopic scale for the selection of optimal process conditions for the removal of $\mathrm{H}_{2} \mathrm{~S}$ from several important gas mixtures including power plant flue gas, natural gas, biogas, tail gas, and acid gas. The framework is developed and 
applied toward achieving the following goals for adsorption-based $\mathrm{H}_{2} \mathrm{~S}$ removal:

- identify the most effective and feasible materials and processes for PSA-based $\mathrm{H}_{2} \mathrm{~S}$ removal from binary gas mixtures (e.g., $\mathrm{CO}_{2} / \mathrm{H}_{2} \mathrm{~S}, \mathrm{H}_{2} \mathrm{~S} / \mathrm{N}_{2}, \mathrm{H}_{2} \mathrm{~S} / \mathrm{CH}_{4}$ )

- obtain high purity and high recovery to limit product losses and greenhouse (GHG) emissions, and

- minimize total investment, operating and material costs.

This is the first study reported in the literature that addresses in a quantitative way the trade-offs at material and process scales for zeolite-based $\mathrm{H}_{2} \mathrm{~S}$ separation. The novel features of our approach also include (i) hierarchical use of shape-, pore- and size-selectivities for zeolite screening for $\mathrm{H}_{2} \mathrm{~S}$ removal, (ii) discovery of zeolites with reverse adsorption selectivities for $\mathrm{H}_{2} \mathrm{~S}$ removal from $\mathrm{CO}_{2} / \mathrm{H}_{2} \mathrm{~S}$ mixtures, (iii) design and optimization of PSA processes for both favorable and reverse adsorption selectivities for $\mathrm{H}_{2} \mathrm{~S}$ removal, (iv) calculation of investment and operating costs to evaluate the performance of PSA-based $\mathrm{H}_{2} \mathrm{~S}$ removal process while satisfying design specifications on both purity and recovery, and (v) detailed mathematical process modeling, rigorous optimization, and combined material selection with process optimization for adsorption-based $\mathrm{H}_{2} \mathrm{~S}$ removal.

\section{Multi-scale Framework}

Our overall in silico screening approach is shown in Fig. 1. We start our analysis with a zeolite database (First, Gounaris, Wei, and Floudas, accessed on August 15, 2015). From this database, we identify potential zeolites based on their pore sizes using ZEOMICS - a three dimensional pore characterization method developed by Floudas and co-workers(First, Gounaris, Wei, and Floudas, 2011). The zeolites are ranked based on shape selectivity (First, Gounaris, and Floudas, 2013), pore selectivity and size selectivity (First, Hasan, and Floudas, 2014). Adsorption isotherms of $\mathrm{H}_{2} \mathrm{~S}$ and other guest molecules are then generated for the top selected structures. These isotherms provide a basis for performing next filtering based on adsorption selectivity. The structures with highest adsorption selectivities are short listed as remaining candidates. For each of these candidate materials, we optimize a PSA process to obtain the optimal separation cost, purity, and recovery. 
The optimized process is obtained by optimizing a detailed PSA model. The purity, recovery and overall separation cost are used as the final metrics to evaluate those zeolites.

[Figure 1 about here.]

A more detailed description of the method at each scale is provided below.

\subsection{Atomistic Scale: Pore Characterization, and Screening based on Shape, Size and Pore Selectivities}

The transport and adsorption of guest molecules inside a zeolite are affected by their shapes, sizes and affinities, as well as by the pore characteristics of the zeolite framework. Therefore, our multiscale screening procedure (shown in Figure 1) starts with a three-dimensional pore characterization method to filter a database of 199 zeolite structures to obtain a short list of candidate zeolites as potential adsorbents for $\mathrm{H}_{2} \mathrm{~S}$ separation. The characterization of the zeolite frameworks is performed using ZEOMICS. Starting from the crystallographic data of a zeolite, ZEOMICS applies graph, geometry, and optimization algorithms to identify portals, channels, cages, and their connectivity. These provide a comprehensive description of the void spaces within a zeolite that molecules such

as $\mathrm{H}_{2} \mathrm{~S}, \mathrm{CO}_{2}, \mathrm{CH}_{4}$ and $\mathrm{N}_{2}$ can access. The description includes pore size distribution, accessible volume, accessible surface area, largest cavity diameter (LCD), and pore limiting diameter (PLD). The framework geometry-based characterization allows us to calculate shape selectivity, size selectivity, and pore selectivity of a gas molecule(e.g., $\mathrm{H}_{2}$ ) with respect to other molecules in a mixture (e.g., $\mathrm{CO}_{2}, \mathrm{~N}_{2}$, or $\mathrm{CH}_{4}$ ).

The three-dimensional shape selectivity of zeolites considers the energetic cost of transport through possible pathways. In the case of a binary gas mixture, shape selectivity describes the difference in energetic cost of transport of two gases through a zeolites pores and their networks due to strain and distortion caused by shape and size (Gounaris, Floudas, and Wei, 2006a; Gounaris, Wei, and Floudas, 2006b; Gounaris, Wei, Floudas, Ranjan, and Tsapatsis, 2009; First, Gounaris, and Floudas, 2013). Depending on the energetic cost, E, of transport, a guest molecule may have free passage $(E=0)$, hindered diffusion (low $E$ ), or no passage (high $E$ ). Shape selectivity, $S_{\text {shape }, A / B} \in[0,1]$, of gas A over gas B, for a given zeolite is, therefore, calculated as the absolute difference in Boltzmann factors of the minimum pathway energies of A and B. For instance, 
considering a binary mixture of $\mathrm{CO}_{2}$ and $\mathrm{H}_{2} \mathrm{~S}$, we compute the shape selectivity between $\mathrm{CO}_{2}$

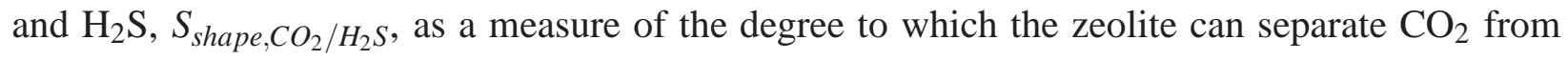
$\mathrm{H}_{2} \mathrm{~S}$ based on hindrance to molecular transport through the most dominant path-way. A value of $S_{\text {shape, } \mathrm{CO}_{2} / \mathrm{H}_{2} \mathrm{~S}} \rightarrow 1$ indicates that $\mathrm{CO}_{2}$ diffusion is severely hindered, while $\mathrm{H}_{2} \mathrm{~S}$ enjoys free passage, and a value of $S_{\text {shape, } \mathrm{CO}_{2} / \mathrm{H}_{2} \mathrm{~S}} \rightarrow 0$ indicates that both $\mathrm{CO}_{2}$ and $\mathrm{H}_{2} \mathrm{~S}$ have similar energetic penalties to travel through the zeolite.

The metric of size selectivity was first introduced by Hasan et al. (Hasan, First, and Floudas, 2013) to consider the entire distribution of pore sizes inside zeolites for carbon capture. While shape selectivity is focused on the most dominant pathway through a zeolite, size selectivity, $S_{\text {size }, A / B} \in[0,1]$, is calculated as the relative difference in accessible pore volume between two gases by approximating the gas molecules as hard spheres to determine accessibility. In adsorptionbased gas separation, size selectivity may determine the separability if the side channels of a zeolite structure play a dominant role.

Pore selectivity, $S_{\text {pore }, A / B} \in[0,1]$, another metric originally proposed for natural gas purification (First, Hasan, and Floudas, 2014), is calculated as the relative difference in energetically-accessible pore volume. The concept of pore selectivity is based on combining the energetic calculations of shape selectivity with the accessible pore volume calculations of size selectivity.

Each of the above metrics is calculated as a number between 0 and 1, with 0 indicating low selectivity and 1 indicating high selectivity. The selectivity values are used to perform a preliminary screening of the large database of zeolites. In this work, minimum cut-off values of $0,0.1$, and 0.1 are introduced for shape, size, and pore selectivity, respectively, to filter the full database of zeolites. Zeolites satisfying one or more of these cut-off values are included for further consideration.

\subsection{Mesoscopic Scale: Molecular Simulation, and Screening based on Ad- sorption Selectivity}

While each of the metrics of shape-, size- and pore-selectivity is readily computed using the automated 3D zeolite pore characterization method, the calculation for adsorption selectivity requires more detailed simulation of equilibrium gas adsorption behavior at the molecular level. Adsorption selectivity is determined by performing grand canonical Monte Carlo (GCMC) simulations to cal- 
culate the Henry constants of gases in each zeolite. We employ the GCMC method in the software package MCCCS Towhee (MCCCS Towhee). The details of the GCMC simulations are reported elsewhere (First, Hasan, and Floudas, 2014). The Henry constant $\left(H_{i, z}\right)$ is useful to understand the interaction between the adsorbate molecule $i$ and the surface of zeolite $z$. We estimate the Henry constant from the pure-component adsorption isotherm generated by GCMC data as follows:

$$
H_{i, z}=\lim _{p \rightarrow 0} \frac{\partial q_{i, z}}{\partial p_{i, z}}=\lim _{q \rightarrow 0} \frac{\partial q_{i, z}}{\partial p_{i, z}}
$$

where $q_{i, z}$ is the molar loading of gas $i$ in equilibrium with a bulk fluid phase at partial pressure $p_{i, z}$ in zeolite $z$. We evaluate the adsorption selectivity, $S_{a d s}$, as follows:

$$
S_{a d s, z}=\frac{q_{C_{2}, z} / p_{C O_{2}, z}}{q_{N_{2}, z} / p_{N_{2}, z}} \approx \frac{H_{C O_{2}, z}}{H_{N_{2}, z}}
$$

\subsection{Process Scale: Optimization of Pressure Swing Adsorption (PSA) Pro- cesses for $\mathrm{H}_{2} \mathrm{~S}$ Separation}

The purpose of the process optimization is to evaluate and compare the performances of top adsorption-selective zeolites for $\mathrm{H}_{2} \mathrm{~S}$ removal. While typical PSA processes refer to above-atmospheric pressure operations, we allow the pressure to go as low as 0.01 bar during desorption. In this context, our PSA process includes both above-atmospheric, atmospheric, and vacuum operations. While PSA and TSA are both suitable, we select PSA over TSA since PSA is often the preferred method for gas separation involving natural gas, carbon capture and many industrially important gases. To fully evaluate the PSA performance for each selected zeolite, we use (i) a 3-step PSA cycle with detailed process configuration, (ii) a detailed model for the PSA process, and (iii) a grey-box constrained optimization method for PSA process optimization.

\subsubsection{PSA Configuration}

The PSA process for $\mathrm{H}_{2} \mathrm{~S}$ removal is illustrated in Fig. 2a. The feed is first compressed to bring it to the desired adsorption pressure. One or more columns packed with zeolite are used for adsorption. For $\mathrm{CO}_{2} / \mathrm{H}_{2} \mathrm{~S}$ and $\mathrm{H}_{2} \mathrm{~S} / \mathrm{CH}_{4}$ mixtures, the clean gas $\left(\mathrm{CO}_{2}\right.$ and $\mathrm{CH}_{4}$, respectively) is collected using a desorption vacuum pump. When we separate $\mathrm{H}_{2} \mathrm{~S}$ from $\mathrm{H}_{2} \mathrm{~S} / \mathrm{N}_{2}$ mixture, $\mathrm{H}_{2} \mathrm{~S}$ is collected using 
the desorption vacuum pump. Multiple adsorption columns are used to maximize the utilization of the feed compressor and the desorption vacuum pump.

[Figure 2 about here.]

PSA is a cyclic process in which each column undergoes a number of operational steps. Even the simplest cycle requires at least two steps, namely adsorption and desorption, but for improved performance, additional steps are used. Our PSA process is operated using a 3-step PSA cycle (Fig. 2b) consisting of (i) column pressurization, (ii) adsorption and (iii) counter-current desorption of the more adsorptive gas. During pressurization, each PSA column is filled with feed gas from the feed-end until the column pressure reaches the adsorption pressure, $P_{a d s}$. During the adsorption step, the other end of the column is kept open so that the less adsorptive gas can exit the column while the more adsorptive gas is adsorbed by the zeolite. During the desorption step, the other end of the column is closed, and the more adsorptive gas is evacuated from the feed-end of the column at the desorption pressure, $P_{d e s}$. A typical pressure profile during a cycle is illustrated in Fig. 2 b.

\subsubsection{PSA Modeling}

The PSA process is modeled using a system of nonlinear algebraic and partial differential equations (NAPDE). These equations describe mass and energy balances, flow through porous media, temperature and pressure effects, and heat transfer resistance across the column wall. The NAPDE model is described below.

Let $i$ represents the components in a binary gas mixture (e.g., $i$ represents $\mathrm{CO}_{2}$ and $\mathrm{H}_{2} \mathrm{~S}$ when a $\mathrm{CO}_{2} / \mathrm{H}_{2} \mathrm{~S}$ mixture is considered). Since the mole fractions must add up to 1 and we consider binary mixtures, the mole fractions in the NAPDE model will be represented in terms of the more adsorbing component. Let, $j$ represents mover (compressors and vacuum pumps), $k$ represents cooler, and $n$ represents column packed with zeolite. The model parameters are defined and described in Table 1.

[Table 1 about here.]

The 5 decision variables for process optimization are $L$ (column length), $P_{a d s}$ (adsorption pressure), $t_{a d s}$ (adsorption time in each cycle) $P_{d e s}$ (desorption pressure), and $t_{d e s}$ (desorption time in 
each cycle). The feed flow rate, feed velocity and column diameter are fixed. The number of required PSA columns is calculated using a procedure described elsewhere (Hasan, Baliban, Elia, and Floudas, 2012b).

We consider the variation both in time $t$ and along the column length $l$. The following system variables are defined to describe the system: $P(l, t)$ for pressure, $T(l, t)$ for temperature, $T_{W}(l, t)$ for column wall temperature, $u_{z}(l, t)$ for velocity, $y_{i}(l, t)$ for mole fraction of component $i$ in the gas phase, $x_{i}(l, t)$ for fractional loading of component $i$ in the solid phase, $x_{i}^{*}(l, t)$ for equilibrium fractional loading of component $i$ in the solid phase, $k_{i}(l, t)$ for mass transfer coefficient of component $i, b_{i}(l, t)$ for temperature dependent parameter for component $i, B_{i}(l, t)$ for an isotherm parameter for component $i, \Delta H_{i}(l, t)$ for the change in internal energy for component $i$, and $\rho_{g}(l, t)$ for the density of gas obtained from the ideal gas law. These system variables remain the same for fixed values of the decision variables. Therefore, the NAPDE model can be treated as a simulation model when all the decision variables are fixed. However, if the decision variables are allowed to change within their lower and upper bounds, then the NAPDE model becomes an optimization model, where the goal is to obtain the optimal decision variables which minimize the total cost while satisfying all process costraints.

We nondimensionalize the NAPDE model by defining the following dimensionless variables: $Z=\frac{l}{L}, \tau=\frac{t u_{o}}{L}, \bar{P}=\frac{P}{P_{a d s}}, \bar{P}_{d e s}=\frac{P_{d e s}}{P_{a d s}}, \bar{T}=\frac{T}{T_{0}}, \bar{T}_{w}=\frac{T_{w}}{T_{0}}, \bar{T}_{a}=\frac{T_{a}}{T_{0}}, x_{i}=\frac{\bar{q}_{i}}{q_{s}}, x_{i}^{*}=\frac{q_{i}^{*}}{q_{s}}$, and $\bar{u}_{z}=\frac{u_{z}}{u_{0}}$.

To calculate the mole fraction of component $i$ in the gas phase, we use a component mass balance:

$$
\frac{\partial y_{i}}{\partial \tau}=\frac{1}{P e}\left(\frac{\partial^{2} y_{i}}{\partial Z^{2}}+\frac{1}{\bar{P}} \frac{\partial y_{i}}{\partial Z} \frac{\partial \bar{P}}{\partial Z}-\frac{1}{\bar{T}} \frac{\partial y_{i}}{\partial Z} \frac{\partial \bar{T}}{\partial Z}\right)-\bar{u}_{z} \frac{\partial y_{i}}{\partial Z}+\frac{\psi \bar{T}}{\bar{P}}\left(\left(y_{i}-1\right) \frac{\partial x_{i}}{\partial \tau}+y_{i} \frac{\partial x_{\mathrm{N}_{2}}}{\partial \tau}\right) \quad \forall i
$$

where $\psi=\left(\frac{1-\varepsilon}{\varepsilon} \frac{R T_{o} q_{s}}{P_{a d s}}\right)$, and $P e=\frac{u_{o} L}{D_{L}}$ is the Peclet number.

Since $\sum_{i} y_{i}=1$, we can write the overall mass balance as follows:

$$
\frac{\partial \bar{P}}{\partial \tau}-\frac{\bar{P}}{\bar{T}} \frac{\partial \bar{T}}{\partial \tau}=\left(-\bar{P} \frac{\partial \bar{u}_{z}}{\partial Z}-\bar{u}_{z} \frac{\partial \bar{P}}{\partial Z}+\bar{u}_{z} \frac{\bar{P}}{\bar{T}} \frac{\partial \bar{T}}{\partial Z}\right)-\bar{T} \psi \frac{\partial}{\partial \tau}\left(\sum_{i} x_{i}\right)
$$

The dimensionless interstitial gas velocity is computed using the following form of Darcy's 
law:

$$
\bar{u}_{z}=-\left(\frac{k_{p} P_{a d s}}{\mu u_{o} L}\right) \frac{\partial \bar{P}}{\partial Z}
$$

Since we allow heat transfer across the column wall, we have:

$$
\frac{\partial \bar{T}_{w}}{\partial \tau}=\pi_{1} \frac{\partial^{2} \bar{T}_{w}}{\partial Z^{2}}+\pi_{2}\left(\bar{T}-\bar{T}_{w}\right)-\pi_{3}\left(\bar{T}_{w}-\bar{T}_{a}\right)
$$

And, the following energy balance is used to compute the temperature inside the column:

$$
\frac{\partial \bar{T}}{\partial \tau}=\pi_{4} \frac{\partial^{2} \bar{T}}{\partial Z^{2}}-\pi_{5} \bar{u}_{z} \frac{\partial \bar{T}}{\partial Z}+\sum_{i=1}^{N}\left(\pi_{6 i}+\pi_{7} \bar{T}\right) \frac{\partial x_{i}}{\partial \tau}-\pi_{8}\left(\bar{T}-\bar{T}_{w}\right)
$$

where $\pi_{1}-\pi_{8}$ are dimensionless parameters, and their complete expressions can be found in the Appendix.

The mass transfer is assumed to depend linearly with the driving force for adsorption loading. The linear driving force (LDF) model is as follows:

$$
\frac{\partial x_{i}}{\partial \tau}=\frac{k_{i} L}{u_{o}}\left(x_{i}^{*}-x_{i}\right) \quad \forall i
$$

The rate constant $\left(k_{i}\right)$ is calcualted using the following expression:

$$
k_{i}=\Omega \frac{\varepsilon D_{p}}{r_{p}^{2}}\left(\frac{c}{q}\right)_{i}
$$

To evaluate $x_{i}^{*}$, we use the following dual-site Langmuir model:

$$
x_{i}^{*}=\sum_{s=1}^{2} \frac{\left(\frac{q_{i, s}^{s a t}}{q_{s}}\right) b_{i, s} c_{i}}{1+\sum_{i} b_{i, s} c_{i}} \quad \forall i
$$

where $q_{i, s}^{s a t}$ is the saturation loading of component $i$ at site $s(s=1, \ldots, 2)$. The temperature dependent parameter $b_{i, s}$ follows the Arrhenius-type expression:

$$
b_{i, s}=\frac{b_{i, s}^{o} e^{-\frac{\Delta U_{i, s}}{R T}}}{R T} \quad \forall(i, s)
$$


Note that a candidate zeolite is represented in the model by the Langmuir parameters describing the adsorption isotherms and heats of adsorption of the gases present in the feed,which are readily available through Grand Canonical Monte Carlo (GCMC) simulation.

We also apply appropriate boundary and initial conditions to describe the three steps, since they are different for different steps. The complete set of initial and boundary conditions for the 3-step PSA process are provided in the Appendix.

To ensure that the PSA process satisfies the minimum purity and recovery specified for the separation, we impose

$$
\begin{gathered}
P u=\frac{\int_{o}^{t_{\text {evac }}} \bar{u}_{z} y_{C O_{2}} \frac{\bar{P}}{R \bar{T}} d t}{\sum_{i} \int_{o}^{t_{\text {evac }}} \bar{u}_{z} y_{i} \frac{\bar{P}}{R \bar{T}} d t} \geq P u_{\text {min }} \\
\operatorname{Re}=\frac{\int_{o}^{t_{\text {evac }}} \bar{u}_{z} y_{C O_{2}} \frac{\bar{P}}{R \bar{T}} d t}{\int_{o}^{t_{p r}} \bar{u}_{z} y_{C O_{2}} \frac{\bar{P}}{R \bar{T}} d t+\int_{o}^{t_{\text {ads }}} \bar{u}_{z} y_{C O_{2}} \frac{\bar{P}}{R \bar{T}} d t} \geq \operatorname{Re}_{\text {min }}
\end{gathered}
$$

The total investment cost, TIC, of the PSA process is calculated as follows:

$$
T I C=\alpha_{c}\left(\bar{W}_{a d s}\right)^{\gamma_{c}}+\alpha_{v}\left(\bar{W}_{d e s}\right)^{\gamma_{v}}+\sum_{n} P C_{n}
$$

where, $\alpha$ and $\gamma$ are the cost parameters obtained from literature(Uppaluri, Linke, and Kokossis, 2004; Hasan, Baliban, Elia, and Floudas, 2012a,b), and $P C_{n}$ is the purchase cost of column $n . \bar{W}_{a d s}$, and $\bar{W}_{d e s}$ are the power requirements of the feed compressor and the desorption vacuum pump, respectively. The expressions for calculating $P C_{n}, \bar{W}_{a d s}$ and $\bar{W}_{d e s}$ are provided in the Appendix.

The annual operating cost, $A O C$, is given by:

$$
A O C=\left[8000 \times 3600 \sum_{j} U C_{j} W_{j}+8000 \times 3600 \sum_{k} U C_{k} W_{k}+U C M \times \frac{\pi}{4} D^{2} L N \rho_{s}\right]
$$

where, $U C_{j}$ is the unit operating cost for equipment $j, W_{j}$ is the duty of equipment $j$ as computed above, and $U C M$ is the unit material cost. We consider 8000 hours as the total annual operation time. 
The objective of the optimization is to minimize the total annualized cost of the overall PSA process:

$$
M I N[\phi T I C+A O C]
$$

where, $\phi$ is the annualizing factor, TIC is the total investment cost, and $A O C$ is the total annual operating cost. The annualizing factor $\phi$ is calculated based on the capital recovery factor, the total plant cost, and the annual maintenance cost. A value of 0.154 is used for the capital recovery factor. The total plant cost includes the total equipment installed costs, the indirect cost, and the balance of plant cost. We consider the indirect cost and the balance of plant cost be $32 \%$ and $20 \%$ of the total installed cost, respectively. The annual maintenance cost is taken to be $5 \%$ of the total plant cost. The installed cost of an equipment includes the equipment purchase cost and the installation cost. We consider the installation costs to be $4 \%$ of the purchase costs for general equipment (columns and heat exchangers) and $80 \%$ of the purchase costs for movers (compressor and vacuum pump) (Fisher, Searcy, Rochelle, Ziaii, and Schubert, 2007). A detailed discussion on the economic parameters and their values used to calculate the investment and operating costs can be found elsewhere (Hasan, Baliban, Elia, and Floudas, 2012a,b).

Equations (3)-(16) define the nonlinear algebraic and partial differential equation-based (NAPDE) model for the optimization of the 3-step PSA process for $\mathrm{H}_{2} \mathrm{~S}$ separation.

\subsubsection{PSA Optimization}

We first identify the most significant input variables which affect the cost, purity and recovery. While the pressurization time is fixed to $20 \mathrm{~s}$ (Hasan, First, and Floudas, 2013), the NAPDE model is optimized to identify the column length $(L)$, adsorption $\left(P_{a d s}\right)$ and desorption $\left(P_{d e s}\right)$ pressures, and adsorption $\left(t_{a d s}\right)$ and desorption $\left(t_{d e s}\right)$ step durations. The column diameter and number of columns are determined using analytical expressions described in Hasan et al. (Hasan, Baliban, Elia, and Floudas, 2012b).

The NAPDE model includes coupled and nonlinear partial differential equations describing the mass and energy balances, time integration in purity and recovery constraints, nonlinear constraints describing the isotherms, and a concave objective function. While the model is detailed 
and accurately captures the equilibrium, kinetic and transport behavior of gas adsorption inside a packed column, it is challenging to solve the model to optimality. In our previous works (Hasan, First, and Floudas, 2013; Hasan, Baliban, Elia, and Floudas, 2012b; First, Hasan, and Floudas, 2014), we introduced an iterative surrogate-based optimization method, where the objective function and the key constraints related to purity and recovery were approximated by multiple Kriging models (Jones, Schonlau, and Welch, 1998; Henao and Maravelias, 2010; Davis and Ierapetritou, 2007). The advantage of such surrogate-based optimization is that the PSA process can be efficiently optimized for different zeolites in a reasonable time. A similar approach is followed in this work, however, a quadratic approximation of the following form is used for the surrogate models representing the objective and constraints.

$$
y^{l}=\beta_{0}^{l}+\sum_{n} \beta_{n}^{l} x_{n}+\sum_{n} \sum_{n^{\prime} \geq n} \beta_{n n^{\prime}}^{l} x_{n} x_{n^{\prime}}
$$

Here, $l$ represents cost, purity, and recovery; $x_{n}$ represents the decision variables $\left(L, P_{a d s}, P_{d e s}, t_{a d s}\right.$, and $t_{d e s}$ ), and $\beta$ are the model parameters which are fitted based on maximum likelihood method using NAPDE simulation data.

We take a discretized version of the NAPDE model to generate samples (i.e., input data required for the development and subsequent improvement of the surrogate model). We simulate the PSA process for different values of the decision variables, and obtain the corresponding cost, purity and recovery values. Each set of fixed decision variables for which the discretized NAPDE model is solved is considered a sample. With this, the optimization encompasses the following aspects: initial sampling based on Latin Hypercube designs (LHD), explicit handling of constraints through individual surrogate models, optimization of quadratic parameters and finally, optimization of the surrogate quadratic model. Initially, a simplified version of the NAPDE model is solved for a limited number of cycles, and a coarser discretization scheme is used to extract useful information about the feasible region of the system. A larger set of simulations of this fast approximation are performed based on LHD, and subsequently a subset of these points is chosen to build the quadratic models. We develop the following three surrogate models:

$$
y^{c}=\beta_{0}^{c}+\sum_{n} \beta_{n}^{c} x_{n}+\sum_{n} \sum_{n^{\prime} \geq n} \beta_{n n^{\prime}}^{c} x_{n} x_{n^{\prime}}
$$




$$
\begin{aligned}
y^{p} & =\beta_{0}^{p}+\sum_{n} \beta_{n}^{p} x_{n}+\sum_{n} \sum_{n^{\prime} \geq n} \beta_{n n^{\prime}}^{p} x_{n} x_{n^{\prime}} \\
y^{r} & =\beta_{0}^{r}+\sum_{n} \beta_{n}^{r} x_{n}+\sum_{n} \sum_{n^{\prime} \geq n} \beta_{n n^{\prime}}^{r} x_{n} x_{n^{\prime}}
\end{aligned}
$$

where, $y^{c}, y^{p}$, and $y^{r}$ are the surrogate variables representing the PSA cost (TIC), purity (Pu), and recovery $(R e)$, respectively. The quadratic model parameters $\left(\beta_{0}^{c}, \beta_{n}^{c}, \beta_{n n^{\prime}}^{c}, \beta_{0}^{p}, \beta_{n}^{p}, \beta_{n n^{\prime}}^{p}, \beta_{0}^{r}, \beta_{n}^{r}, \beta_{n n^{\prime}}^{r}\right)$ are identified via least-squares error minimization to produce quadratic surrogate models separately for cost, purity and recovery. For instance, the nonlinear (NLP) error minimization problem to produce the surrogate model for the cost is described as follows:

$$
\operatorname{MIN} \sum_{i}\left(\frac{T I C^{i}-y^{i, c}}{T I C^{i}}\right)^{2}
$$

s.t.

$$
y^{i, c}=\beta_{0}^{c}+\sum_{n} \beta_{n}^{c} x_{i, n}+\sum_{n} \sum_{n^{\prime} \geq n} \beta_{n n^{\prime}}^{c} x_{i, n} x_{i, n^{\prime}}
$$

where, $i$ represents a sample and $T I C^{i}$ is the original cost value at sample $i$ obtained from NAPDE simulation. Similar NLP problems are solved to generate surrogate functions for purity and recovery.

Subsequently, the optimization of the surrogate models is performed. The surrogate-based PSA optimization is defined as:

$$
\operatorname{MIN} y^{c}
$$

s.t.

$$
\begin{array}{r}
y^{c}=\beta_{0}^{c}+\sum_{n} \beta_{n}^{c} x_{n}+\sum_{n} \sum_{n^{\prime} \geq n} \beta_{n n^{\prime}}^{c} x_{n} x_{n^{\prime}} \\
y^{p}=\beta_{0}^{p}+\sum_{n} \beta_{n}^{p} x_{n}+\sum_{n} \sum_{n^{\prime} \geq n} \beta_{n n^{\prime}}^{p} x_{n} x_{n^{\prime}} \\
y^{r}=\beta_{0}^{r}+\sum_{n} \beta_{n}^{r} x_{n}+\sum_{n} \sum_{n^{\prime} \geq n} \beta_{n n^{\prime}}^{r} x_{n} x_{n^{\prime}} \\
y^{p} \geq P u_{\text {min }} \\
y^{r} \geq R e_{\text {min }}
\end{array}
$$


New sampling of the NAPDE model is performed at the solution. The above steps are performed iteratively until a convergence is met related to the accuracy of the approximation and consecutive iteration improvement. The parameter estimation and optimization of the surrogate models are performed in GAMS. There is a possibility that the surrogate optimization may not have a feasible solution in terms of purity or recovery or both. In that case, we solve the following alternative model to generate the new sample, where the priority is set to obtain solutions with purity and recovery values as close as possible to the minimum specified values.

$$
\operatorname{MIN}\left(y^{p}-P u_{\text {min }}\right)^{2}+\left(y^{r}-R e_{\text {min }}\right)^{2}
$$

s.t.

$$
\begin{aligned}
y^{p} & =\beta_{0}^{p}+\sum_{n} \beta_{n}^{p} x_{n}+\sum_{n} \sum_{n^{\prime} \geq n} \beta_{n n^{\prime}}^{p} x_{n} x_{n^{\prime}} \\
y^{r} & =\beta_{0}^{r}+\sum_{n} \beta_{n}^{r} x_{n}+\sum_{n} \sum_{n^{\prime} \geq n} \beta_{n n^{\prime}}^{r} x_{n} x_{n^{\prime}}
\end{aligned}
$$

Using the above strategy, the optimal purity, recovery and process costs are obtained for selected zeolites. Cost is used as the final metric to obtain a ranked ordered list of the most promising zeolites for $\mathrm{H}_{2} \mathrm{~S}$ removal. We rank the feasible zeolites, which satisfy the minimum purity and recovery constraints, according to cost in decreasing order.

\section{Results \& Discussion}

In this work, 199 existing zeolites are considered for screening. The zeolites data are taken from the ZEOMICS database (First, Gounaris, Wei, and Floudas, accessed on August 15, 2015). Selectivities are calculated based on $\mathrm{CO}_{2}$ for $\mathrm{CO}_{2} / \mathrm{H}_{2} \mathrm{~S}$ mixture, and $\mathrm{H}_{2} \mathrm{~S}$ for both $\mathrm{H}_{2} \mathrm{~S} / \mathrm{N}_{2}$ and $\mathrm{H}_{2} \mathrm{~S}_{/} / \mathrm{CH}_{4}$

mixtures. All shape and pore selectivities are calculated at $298 \mathrm{~K}$. Minimum cut-off values of $0,0.1$, and 0.1 are introduced for shape, size, and pore selectivity, respectively, to filter the full database of zeolites. The multi-scale framework is applied for different separation systems involv- 
ing $\mathrm{H}_{2} \mathrm{~S}$. The results are discussed below.

\section{1 $\mathrm{H}_{2} \mathrm{~S}$ removal from $\mathrm{CO}_{2} / \mathrm{H}_{2} \mathrm{~S}$ Mixture}

We consider the removal of $\mathrm{H}_{2} \mathrm{~S}$ from a feed acid gas $\left(\mathrm{CO}_{2} / \mathrm{H}_{2} \mathrm{~S}\right)$ mixture containing $5 \% \mathrm{H}_{2} \mathrm{~S}$. The feed flow rate is $0.1 \mathrm{kmol} / \mathrm{s}$. We would like to purify $\mathrm{CO}_{2}$ with a minimum purity of $98 \%$. Most importantly, we also want to reduce the loss of $\mathrm{CO}_{2}$ during the separation. A minimum recovery target of $90 \%$ for $\mathrm{CO}_{2}$ is set. Therefore, the objective is to identify the most cost-effective zeolites and the optimum PSA process which would separate $\mathrm{CO}_{2}$ with at least $98 \%$ purity and $90 \%$ recovery from the feed acid gas mixture. This is a challenging problem for several reasons. First, $\mathrm{CO}_{2}$ and $\mathrm{H}_{2} \mathrm{~S}$ are both acid gases, and exhibit similar afffinities. Second, although the change in $\mathrm{CO}_{2}$ purity is not very significant, the requirement for both extremely high purity and high recovery makes the $\mathrm{H}_{2} \mathrm{~S}$ removal a challenging task. The trade-off between purity and recovery often prohibits a separation process to obtain a product with both high purity and high recovery.

Applying our computational framework, we have identified 57 out of 199 zeolites which show either shape selectivity, size selectivity or pore selectivity for $\mathrm{CO}_{2}$ over $\mathrm{H}_{2} \mathrm{~S}$. Among the 57 zeolites, which exhibit shape/size/pore selectivity for $\mathrm{CO}_{2}$, only 15 of them show favorable adsorption selectivity for $\mathrm{CO}_{2}$ (i.e., $\mathrm{S}_{a d s, \mathrm{CO}_{2} / \mathrm{H}_{2} S}>1$ ), while 42 zeolites show moderate to high adsorption selectivity for $\mathrm{H}_{2} \mathrm{~S}\left(\mathrm{~S}_{a d s, \mathrm{H}_{2} S / \mathrm{CO}_{2}}>1\right)$. Tables 2 and 3 report the most selective zeolites for $\mathrm{CO}_{2} / \mathrm{H}_{2} \mathrm{~S}$ separation, arranged in decreasing order of adsorption selectivity for $\mathrm{CO}_{2}$. The zeolites listed in Table 2 have $\mathrm{CO}_{2}$ adsorption selectivities higher than 1, while the zeolites listed in Table 3 have $\mathrm{H}_{2} \mathrm{~S}$ adsorption selectivities higher than 1 . This reverse selectivity for $\mathrm{CO}_{2}$ is in contrast to the typical adsorption characteristics considered for microporous materials. It is typically considered that in micorporous materials, the adsorption affinities for gases follow: $\mathrm{CO}_{2}>\mathrm{H}_{2} \mathrm{~S}>\mathrm{CH}_{4}>\mathrm{N}_{2}$. However, we observe that zeolites may also exhibit adsorption selectivity in favor of $\mathrm{H}_{2} \mathrm{~S}$ (Table 3 ).

[Table 2 about here.]

[Table 3 about here.]

The observation of many $\mathrm{H}_{2} \mathrm{~S}$-selective zeolites has important implications in the design and optimization of PSA processes for $\mathrm{CO}_{2} / \mathrm{H}_{2} \mathrm{~S}$ separation. First, due to the change in selectivity 
from $\mathrm{CO}_{2}$ to $\mathrm{H}_{2} \mathrm{~S}, \mathrm{CO}_{2}$ would no longer be preferably adsorbed inside the column. The PSA design would need to consider more $\mathrm{H}_{2} \mathrm{~S}$ adsorption during the adsorption step than $\mathrm{CO}_{2}$. Second, instead of $\mathrm{CO}_{2}, \mathrm{H}_{2} \mathrm{~S}$ would be extracted during the desorption step. Third, the product $\mathrm{CO}_{2}$ would be obtained in a different step. The final product $\mathrm{CO}_{2}$ pressure would be also different. Fourth, the purity and recovery constraints would need to be implemented differently. When $\mathrm{CO}_{2}$ is more adsorptive, then these constraints are imposed on the $\mathrm{CO}_{2}$ out flows during the desorption step. However, when $\mathrm{H}_{2} \mathrm{~S}$ is more adsorptive, then the constraints must be imposed on the $\mathrm{CO}_{2}$ out flows from the opposite end of the column during the adsorption step. Fifth, since the feed typically contains less $\mathrm{H}_{2} \mathrm{~S}$ than $\mathrm{CO}_{2}$ in terms of molar flow rates, the operating and investment costs for $\mathrm{H}_{2} \mathrm{~S}$ selective PSA processes would be different than those of the $\mathrm{CO}_{2}$ selective PSA processes, even when the composition of the feed mixture remains the same.

Therefore, we have considered two different PSA configurations to address both typical $\left(\mathrm{CO}_{2}\right.$ selective) and reverse ( $\mathrm{H}_{2} \mathrm{~S}$-selective) zeolites. The PSA configuration shown in Fig. 3a is developed for $\mathrm{CO}_{2}$-selective zeolites, where $\mathrm{H}_{2} \mathrm{~S}$ leaves the column during adsorption and $\mathrm{CO}_{2}$ is extracted as product during desorption. The purity and recovery constraints are imposed on the $\mathrm{CO}_{2}$ flows at the feed end of the column during desorption at vacuum, $P_{d e s}$.

The PSA configuration illustrated in Fig. 3 b considers $\mathrm{H}_{2} \mathrm{~S}$-selective zeolites, where $\mathrm{CO}_{2}$ is extracted as product at the far end of the column during the adsorption step, while $\mathrm{H}_{2} \mathrm{~S}$ is first desorbed from the column at the feed end of the column using the vacuum pump, and then left as concentrated $\mathrm{H}_{2} \mathrm{~S}$ stream during the desorption step. The purity and recovery constraints are imposed on the $\mathrm{CO}_{2}$ flows at the far end of the column during adsorption at highest pressure, $P_{a d s}$.

[Figure 3 about here.]

For both process configurations, we consider the same feed mixture with the same target separation while optimizing the total annualized cost (TAC) of the PSA process. TAC includes the investment, operating and material costs.

The results for $\mathrm{CO}_{2}$-selective zeolites are shown in Table 4. Through multi-scale modeling, simulation and optimization, we have identified 4 zeolites (BIK, NSI, AEN, MON) as the top $\mathrm{CO}_{2^{-}}$ selective zeolites for $\mathrm{H}_{2} \mathrm{~S}$ removal. Each of these four zeolites can remove $\mathrm{H}_{2} \mathrm{~S}$ while satisfying the $\mathrm{CO}_{2}$ purity and recovery of $98 \%$ and $90 \%$, respectively. BIK is the top zeolite which separates 
$\mathrm{CO}_{2}$ from the $\mathrm{H}_{2} \mathrm{~S} / \mathrm{CO}_{2}$ mixture with $98 \%$ purity nad $92 \%$ recovery at a total cost of $\$ 3.35 \mathrm{MM}$ for every $0.1 \mathrm{kmol} / \mathrm{s}$ of the feed.

[Table 4 about here.]

The optimal design of the PSA columns remain the same for all zeolites. The column lengths are selected to be the shortest length allowed (i.e., 1 meter) for all cases. While smaller columns are possible, a further reduction in column length would decrease the $L / D$ ratio to an operationally impractical level. The desorption pressure is 0.01 bar in most cases, highlighting that unless the columns are regenerated at deep vacuum, the desired recovery would not be attained. The majority of the energy consumed in PSA process is attributed to the vacuum regeneration of the adsorbents. The desorption is preferred to occur at low vacuum, which can be the consequence of sharp isotherm curvatures of the more adsorbing component (in this case, $\mathrm{CO}_{2}$ ) at low partial pressures. The same phenomenon was observed in our previous study on $\mathrm{CO}_{2} / \mathrm{N}_{2}$ separation (Hasan, First, and Floudas, 2013). The adsorption times are found to be much shorter than the desorption times.

Interestingly, BIK, NSI and AEN zeolites were also previously identified as top materials for $\mathrm{CH}_{4}$ purification from $\mathrm{CO}_{2} / \mathrm{CH}_{4}$ mixtures (First, Hasan, and Floudas, 2014). Therefore, we anticipate that these zeolites will be excellent candidates for $\mathrm{CH}_{4}$ separation from ternary mixtures containing $\mathrm{CH}_{4}, \mathrm{CO}_{2}$ and $\mathrm{H}_{2} \mathrm{~S}$. They will provide cost-effective and single-step acid gas removal (both $\mathrm{CO}_{2}$ and $\mathrm{H}_{2} \mathrm{~S}$ ) from sour natural gas, shale gas, biogas, and landfill gas.

For comparison, we further list the top zeolites involving $\mathrm{CO}_{2}$ separation from $\mathrm{H}_{2} \mathrm{~S}_{1} \mathrm{CH}_{4}$ and $\mathrm{N}_{2}$ in Table 5, based on the results obtained in this work and by (First, Hasan, and Floudas, 2014) and (Hasan, First, and Floudas, 2013). We observe that ABW ranks in top ten for all three important separations $\left(7^{\text {th }}\right.$ in $\mathrm{H}_{2} \mathrm{~S}$ removal from acid gases, $7^{\text {th }}$ in natural gas purification, and $4^{\text {th }}$ in carbon capture). Therefore, ABW shows high potential for commercialization as an adsorbent for multiple applications, including acid gas removal from natural gas.

[Table 5 about here.]

We also optimized PSA processes for the zeolites which show more adsorption affinity toward $\mathrm{H}_{2} \mathrm{~S}$ than that for $\mathrm{CO}_{2}$. We consider the same feed composition to evaluate these zeolites. The top zeolites with reverse selectivity are listed along with their optimal PSA performance in Table 6. 
Results suggest that $\mathrm{H}_{2} \mathrm{~S}$-selective zeolites (Table 6) can be in fact more effective than $\mathrm{CO}_{2}$ selective zeolites for $\mathrm{H}_{2} \mathrm{~S}$ removal from $\mathrm{CO}_{2} / \mathrm{H}_{2} \mathrm{~S}$ mixtures (Table 4). We have identified three novel zeolites (TOL, TON, and MOR) which cost-effectively separate $\mathrm{CO}_{2}$ from $\mathrm{H}_{2} \mathrm{~S}$ with $98 \%$ purity and $90 \%$ recovery for $\mathrm{CO}_{2}$. The top $\mathrm{H}_{2} \mathrm{~S}$-selective zeolite is TOL which separates $\mathrm{CO}_{2}$ from $\mathrm{H}_{2} \mathrm{~S}$ with $98 \% \mathrm{CO}_{2}$ purity and $93 \%$ recovery at a cost of $\$ 2.11$ million, which is $37 \%$ less than the cost estimated for the best $\mathrm{CO}_{2}$-selective zeolite BIK. In fact, all three $\mathrm{H}_{2} \mathrm{~S}$-selective zeolites which are feasible for the separation have less separation cost than that of BIK. This is a non-intuitive result obtained for the first time which shows that it is possible to perform cost-effective $\mathrm{H}_{2} \mathrm{~S}$ removal by exploiting reverse selectivity of the gas molecules using novel microporous materials.

[Table 6 about here.]

The regeneration of the PSA columns significantly contributes to the energy consumption and cost. The desorption pressure is a key factor that governs the energy consumption toward achieving a more cost-effective separation. It is observed that the $\mathrm{H}_{2} \mathrm{~S}$-selective zeolites are capable of removing $\mathrm{H}_{2} \mathrm{~S}$ by desorbing $\mathrm{H}_{2} \mathrm{~S}$ at elevated pressures (0.02-0.04 bar) compared to the desorption pressures (0.005-0.01 bar) required for $\mathrm{CO}_{2}$ by the $\mathrm{CO}_{2}$-selctive zeolites. Since the vacuum pump needs to achieve a significantly large pressure ratio $\left(P_{\text {atm }} / P_{\text {des }}\right)$ compared to the pressure ratio for feed compression $\left(P_{a d s} / P_{a t m}\right)$, even a slight improvement in the desorption pressure $\left(P_{\text {des }}\right)$ is highly desirable. To illustrate, the change of $P_{\text {des }}$ from 0.01 to 0.02 bar reduces the pressure ratio by half from 100 to 50 for the vacuum pump which has a constant outlet pressure of 1 bar. This in turn significantly reduces the energy consumption and cost. While regenerating the column at higher pressure reduces the cost, we also need to remember that this reduces the purity and recovery. Therefore, it is important to perform detailed process optimization in tandem with material selection to appropriately address the trade-offs.

\section{2 $\mathrm{H}_{2} \mathrm{~S}$ removal from $\mathrm{H}_{2} \mathrm{~S} / \mathrm{N}_{2}$ Mixture}

64 candidate zeolites are screened as preliminary candidates for $\mathrm{H}_{2} \mathrm{~S}$ removal from $\mathrm{H}_{2} \mathrm{~S} / \mathrm{N}_{2}$ mixture, which exhibit either shape, size and pore selectivity. Table 7 provides the list of the top candidate zeolites for the separation of $\mathrm{N}_{2}$ from a $\mathrm{H}_{2} \mathrm{~S} / \mathrm{N}_{2}$ mixture. Among the 64 zeolites, which 
meet the minimum cut-off values for at least one of the selectivities (shape, size, pore and adsorption selectivities of $\mathrm{H}_{2} \mathrm{~S}$ over $\mathrm{N}_{2}$ ), the top 31 zeolites are listed in Table 7 which exhibit $\mathrm{H}_{2} \mathrm{~S}$ adsorption selectivity of 50 or more.

[Table 7 about here.]

The top zeolites according to their process performance for $\mathrm{H}_{2} \mathrm{~S} / \mathrm{N}_{2}$ separation are listed in Table 8. These results are based on feed containing $10 \% \mathrm{H}_{2} \mathrm{~S}$ and $90 \% \mathrm{~N}_{2}$. Four zeolites (ATV, AWO, MER and BRE) can separate $\mathrm{N}_{2}$ with $99 \%$ purity and more than $90 \%$ recovery. ATV, the best zeolite for $\mathrm{H}_{2} \mathrm{~S} / \mathrm{N}_{2}$ separation, can separate $\mathrm{N}_{2}$ with $99 \%$ purity and $94 \%$ recovery. The highest purity of $99.99 \%$ is achieved by SOD, highlighting the fact that zeolite-based adsorption can perform ultra-purity separation. However, such separation has lower recovery (about 86\%), which signifies the trade-off between purity and recovery in a separation process.

The design of the PSA columns is found to be similar to other separations. The column length is selected to be 1 meter for all cases, which is the lowest value allowed for the length during separation. The adsorption times are at least 2 to 3 times shorter than the desorption times for most zeolites. The desorption pressures $(0.01-0.04$ bar $)$ are also found in the similar the range identified for $\mathrm{CO}_{2} / \mathrm{H}_{2} \mathrm{~S}$ separation as discussed earlier. Again, majority of the energy consumed in PSA process are attributed to the vacuum regeneration of the adsorbents.

[Table 8 about here.]

\section{3 $\mathrm{H}_{2} \mathrm{~S}$ removal from $\mathrm{H}_{2} \mathrm{~S} / \mathrm{CH}_{4}$ Mixture}

Out of 199 zeolites, 29 zeolites show shape selectivity, 26 zeolites show size selectivity, and 33 zeolites show pore selectivity higher than 0.1 for $\mathrm{H}_{2} \mathrm{~S}$ for $\mathrm{H}_{2} \mathrm{~S} / \mathrm{CH}_{4}$ system. All 33 zeolites which are pore-selective also show shape and size selectivities for this separation. Table 9 lists the top candidate zeolites for the separation of $\mathrm{H}_{2} \mathrm{~S}$ from a $\mathrm{H}_{2} \mathrm{~S} / \mathrm{CH}_{4}$ mixture. Only 13 zeolites meet one or more selectivity criteria.

[Table 9 about here.] 
We consider a methane source which is contaminated by $5 \% \mathrm{H}_{2} \mathrm{~S}$. The objective is to reduce the $\mathrm{H}_{2} \mathrm{~S}$ level to less than $2 \%$ while recovering $90 \%$ of the methane from the feed. We have investigated the top zeolites suggested by the materials-centric metrics, and found that the zeolite MER is a promising zeolite which has not been suggested in any previous studies for $\mathrm{H}_{2} \mathrm{~S}$ separation for removing $\mathrm{H}_{2} \mathrm{~S}$ from natural gas $\left(\mathrm{CH}_{4}\right)$. MER can increase the purity of $\mathrm{CH}_{4}$ from $95 \%$ to $99.99 \%$, while recovering $90 \%$ of the $\mathrm{CH}_{4}$ fed to the PSA process.

The costs of the PSA processes described in this work are obtained for fixed economic parameters. While the absolute costs are sensitive to the values used for the economic parameters, the overall ranking of the zeolites do not change significantly. Similar observations were made in previous studies related to $\mathrm{CO}_{2}, \mathrm{~N}_{2}$, and $\mathrm{CH}_{4}$ (Hasan, First, and Floudas, 2013; First, Hasan, and Floudas, 2014). Furthermore, the shape, size and pore selectivity-based rankings are not sensitive to the equilibrium parameters, as they do not depend on the nature of the adsorption isotherms. However, the absolute purity and recovery values may change if the isotherm parameters are changed significantly.

\section{Conclusions}

Using the combined material screening and process optimization methodology, we have discovered several new zeolites for removing $\mathrm{H}_{2} \mathrm{~S}$ from a variety of industrial gas mixtures with applications in carbon capture, acid gas removal, natural gas purification and tail gas purification. We have identified TOL, TON, MOR, BIK, NSI, AEN, and MON to be the most cost-effective zeolites for $\mathrm{H}_{2} \mathrm{~S}$ removal from acid gas. We have also found several novel zeolites for $\mathrm{H}_{2} \mathrm{~S}$ removal from nitrogen and methane. The PSA process can achieve $\mathrm{CO}_{2}$ purity to $98-99 \%$ with $\mathrm{CO}_{2}$ recovery of 90 - $94 \%$ for $95 / 5 \% \mathrm{CO}_{2} / \mathrm{H}_{2} \mathrm{~S}$ system, $10 / 90 \% \mathrm{H}_{2} \mathrm{~S} / \mathrm{N}_{2}$ system, and $99.99 \%$ purity and $90 \%$ recovery for $5 / 95 \% \mathrm{H}_{2} \mathrm{~S} / \mathrm{CH}_{4}$ system. The costs of separation are also reasonable. Lowest adsorption and desorption pressures, fast adsorption but slow desorption are found to be effective for adsorptionbased $\mathrm{H}_{2} \mathrm{~S}$ removal using zeolites. Several zeolites are identified with potential for commercial use. Especially, zeolite $\mathrm{ABW}$ ranks as one of the top materials for the removal of both $\mathrm{H}_{2} \mathrm{~S}$ and $\mathrm{CO}_{2}$ (acid gases) from natural gas. It has been found that cost-effective $\mathrm{H}_{2} \mathrm{~S}$ removal can be obtained by exploiting reverse selectivity of $\mathrm{H}_{2} \mathrm{~S}$ over $\mathrm{CO}_{2}$ in zeolites. All screened zeolites are among the 
top materials for gas sweetening and $\mathrm{H}_{2} \mathrm{~S}$ removal from natural gas, acid gas, tail gas, flue gas, refinery gas, biogas, landfill gas, and other gases of industrial importance. We anticipate that our approach is suitable for the discovery of novel materials for other molecular gas separation.

\section{Acknowledgments}

This work was partially supported by the National Science Foundation under awards EFRI-0937706 and CBET-1263165. E.L.F. is thankful for his National Defense Science and Engineering Graduate (NDSEG) fellowship. A portion of the computation was performed at the TIGRESS high performance computer center at Princeton University. Tingting Liu acknowledges support from the China Scholarship Council, CSC, (No. 201306880009). 


\section{Appendix}

A1. Dimensionless groups in the NAPDE model

$$
\begin{gathered}
\pi_{1}=\frac{K_{w}}{\rho_{w} C_{p w} u_{o} L} \\
\pi_{2}=\frac{2 r_{i} h_{i n} L}{\rho_{w} C_{p w} u_{o}\left(r_{o}^{2}-r_{i n}^{2}\right)} \\
\pi_{3}=\frac{2 r_{o} h_{o} L}{\rho_{w} C_{p w} u_{o}\left(r_{o}^{2}-r_{i n}^{2}\right)} \\
\pi_{4}=\frac{K_{z}}{\varepsilon\left(\rho_{g} C_{p g}+\frac{1-\varepsilon}{\varepsilon}\left(\rho_{s} C_{p s}+C_{p a} q_{s}\right)\right) u_{o} L} \\
\pi_{6 i}=\frac{\rho_{g} C_{p g}}{\left(\rho_{g} C_{p g}+\frac{1-\varepsilon}{\varepsilon}\left(\rho_{s} C_{p s}+C_{p a} q_{s}\right)\right)} \\
\pi_{8}=\frac{\frac{1-\varepsilon}{\varepsilon}\left(-\Delta H_{i}\right) q_{s}}{\left.\varepsilon \rho_{i} C_{p g}+\frac{1-\varepsilon}{\varepsilon}\left(\rho_{s} C_{p s}+C_{p a} q_{s}\right)\right)} \\
\pi_{7}=\frac{\Delta H_{i}=\Delta U_{i}-R T}{T_{0}\left(\rho_{g} C_{p g}+\frac{1-\varepsilon}{\varepsilon}\left(\rho_{s} C_{p s}+C_{p a} q_{s}\right)\right)} \\
\frac{1-\varepsilon}{\varepsilon}\left(C_{p g}-C_{p a}\right) T_{0} q_{s}
\end{gathered}
$$

\section{A2. Initial and Boundary Conditions for the 3-Step PSA}

Pressurization: The initial conditions for the first pressurization step are given by equation (35).

$$
\begin{aligned}
y_{i} & =y_{i, 0} \\
\bar{P} & =\bar{P}_{d e s} \\
\bar{T} & =1 \\
x_{i} & =\left.x_{i}^{*}\right|_{y_{i, 0}}
\end{aligned}
$$

Let $\mathrm{Z}=0^{+}$and $\mathrm{Z}=1^{-}$be the two ends of an adsorption column where the boundary conditions 
must be applied. The boundary conditions at $\mathrm{Z}=0^{+}$for the pressurization step are as follows:

$$
\begin{aligned}
& \frac{1}{P e} \frac{\partial y_{i}}{\partial Z}=-\bar{u}_{z}\left(y_{i, f}-y_{i}\right) \\
& \frac{1}{P e_{H}} \frac{\partial \bar{T}}{\partial Z}=-\bar{u}_{z}(1-\bar{T}) \\
& \bar{T}_{w}=\bar{T}_{a} \\
& \bar{P}=f(\tau) ; \bar{P}_{d e s} \rightarrow 1
\end{aligned}
$$

The boundary conditions at $\mathrm{Z}=1^{-}$are:

$$
\begin{aligned}
& \frac{\partial y_{i}}{\partial Z}=0 \\
& \frac{\partial \bar{T}}{\partial Z}=0 \\
& \bar{T}_{w}=\bar{T}_{a} \\
& \frac{\partial \bar{P}}{\partial Z}=0
\end{aligned}
$$

Adsorption: The boundary conditions at $\mathrm{Z}=0^{+}$and $\mathrm{Z}=1^{-}$for the adsorption step are given by equations (38) and (39), respectively.

$$
\begin{gathered}
\frac{\partial y_{i}}{\partial Z}=-P e\left(y_{i, f}-y_{i}\right) \\
\frac{1}{P e_{H}} \frac{\partial \bar{T}}{\partial Z}=-(1-\bar{T}) \\
\bar{T}_{w}=\bar{T}_{a} \\
\bar{P}=1+\frac{\Delta}{P_{a d s}} \\
\frac{\partial y_{i}}{\partial Z}=0 \\
\frac{\partial \bar{T}}{\partial Z}=0 \\
\bar{T}_{w}=\bar{T}_{a} \\
\bar{P}=1
\end{gathered}
$$

where $\Delta$ is a user defined paramater to set the pressure drop across the bed, and $P e_{H}=\frac{\varepsilon u_{o} L \rho_{g} C_{p g}}{K_{z}}$. Desorption: The boundary conditions at $\mathrm{Z}=0^{+}$and $\mathrm{Z}=1^{-}$for the evacuation step are given 
by equations (40) and (41), respectively.

$$
\begin{gathered}
\frac{\partial y_{i}}{\partial Z}=0 \\
\frac{\partial \bar{T}}{\partial Z}=0 \\
\bar{T}_{w}=\bar{T}_{a} \\
\frac{\partial \bar{P}}{\partial Z}=0 \\
\frac{\partial y_{i}}{\partial Z}=0 \\
\frac{\partial \bar{T}}{\partial Z}=0 \\
\bar{T}_{w}=\bar{T}_{a} \\
\bar{P}=f(\tau): \bar{P}_{a d s} \rightarrow \bar{P}_{d e s}
\end{gathered}
$$

\section{A3. Expressions for Calculting Power consumption}

$$
\begin{gathered}
\bar{W}_{a d s}=\frac{W_{a d s}}{t_{a d s} \times 746} \\
\bar{W}_{d e s}=\frac{W_{d e s}}{t_{d e s} \times 746} \\
W_{a d s}=\frac{1}{\eta} \varepsilon \pi D^{2} u_{0} P_{a d s} \frac{\gamma}{\gamma-1} \int_{o}^{t_{a d s}}\left(\left.\bar{u}_{Z} \bar{P}\right|_{Z=0}\right)\left[\left(\frac{\left.P_{a d s} \bar{P}\right|_{Z=0}}{P_{f}}\right)^{\frac{\gamma-1}{\gamma}}-1\right] d t \\
W_{d e s}=\frac{1}{\eta} \varepsilon \pi D^{2} u_{0} P_{a d s} \frac{\gamma}{\gamma-1} \int_{o}^{t_{\text {des }}}\left(\left.\bar{u}_{z} \bar{P}\right|_{Z=0}\right)\left[\left(\frac{P_{a t m}}{\left.P_{a d s} \bar{P}\right|_{Z=0}}\right)^{\frac{\gamma-1}{\gamma}}-1\right] d t
\end{gathered}
$$

\section{A4. Expressions for Cost Calculations}

The purchase cost $\left(P C_{n}\right)$ of column $n$ is calculated using the following expressions:

$$
P C_{n}=F_{M} C_{V, n}+C_{P L, n}+V_{P, n} C_{P K}+C_{D R, n}
$$

where $F_{M}$ is the factor for materials-of-construction, $C_{V, n}$ is the free-on-board (f.o.b.) purchase cost of empty vessel with the weight $W_{n}, C_{P L, n}$ is the added cost for adsorber platforms and ladders, $V_{P, n}$ is the adsorber packing volume, $C_{P K}$ is the installed cost of the packing for unit volume, and $C_{D R, n}$ 
is the installed cost of flow distributors and redistributors of column $n$. These are expressed as follows:

$$
\begin{gathered}
C_{V, n}=\exp \left\{7.2756+0.18255 \ln \left(W_{n}\right)+0.02297\left[\ln \left(W_{n}\right)\right]^{2}\right\} \\
W_{n}=\pi\left(39.37 D_{n}+t_{S}\right)\left[39.37\left(0.8 D_{n}+L_{n}\right)\right] t_{S} \rho \\
C_{P L, n}=300.9\left(3.281 D_{n}\right)^{0.63316}\left(3.281 L_{n}\right)^{0.80161} \\
V_{P, n}=\frac{\pi}{4}\left(3.281 D_{n}\right)^{2}\left(3.281 L_{n}\right) \\
C_{D R, n}=3 \times 125 \times \frac{\pi}{4}\left(3.281 D_{n}\right)^{2}
\end{gathered}
$$

where $L_{n}$ and $D_{n}$ are the length and diameter of column $n, t_{S}$ is the shell thickness, and $\rho$ is the density of the carbon steel. We use $F_{M}=2.1, C_{P K}=40, \rho=0.284 \mathrm{lb} / \mathrm{in}^{3}$, and $t_{S}=2$.

\section{A5. Cost Breakdown Results}

The following Table provides the breakdown of the costs and the compressor work duties for $\mathrm{H}_{2} \mathrm{~S} / \mathrm{CO}_{2}, \mathrm{H}_{2} \mathrm{~S} / \mathrm{N}_{2}$, and $\mathrm{H}_{2} \mathrm{~S} / \mathrm{CH}_{4}$ separations:

[Table 10 about here.] 


\section{Literature Cited}

A. Agarwal, L. T. Biegler, and S. E. Zitney. A superstructure-based optimal synthesis of psa cycles for post-combustion $\mathrm{CO}_{2}$ capture. AIChE J., 56(7):1813-1828, 2010.

S. R. Alexander and J. Winnick. Removal of hydrogen sulfide from natural gas through an electrochemical membrane separator. AIChE J., 40(4):613-620, 1994.

A. Burke, J. Winnick, C. Xia, and M. Liu. Removal of hydrogen sulfide from a fuel gas stream by electrochemical membrane separation. Journal of The Electrochemical Society, 149(11): D160-D166, 2002.

T. Cnop, D. Dortmundt, and M. Schott. Continued development of gas separation membranes for highly sour service, 2007.

D. A. Dalrymple, T. W. Trofe, and D. Leppin. Gas industry assesses new ways to remove small amounts of $\mathrm{H}_{2}$ S. Oil \& Gas Journal, Tulsa, May 23, 1994.

E. Davis and M. Ierapetritou. A kriging method for the solution of nonlinear programs with blackbox functions. AIChE J., 53(8):2001-2012, 2007.

E. L. First, C. E. Gounaris, J. Wei, and C. A. Floudas. Computational characterization of zeolite porous networks: an automated approach. Phys. Chem. Chem. Phys., 13:17339-17358, 2011. doi: $10.1039 / \mathrm{c} 1 \mathrm{cp} 21731 \mathrm{c}$.

E. L. First, C. E. Gounaris, and C. A. Floudas. Predictive framework for shape-selective separations in three-dimensional zeolites and metal-organic frameworks. Langmuir, 29(18):5599-5608, 2013. doi: 10.1021/la400547a.

E. L. First, M. M. F. Hasan, and C. A. Floudas. Discovery of novel zeolites for natural gas purification through combined material screening and process optimization. AIChE J., 60(5):1767$1785,2014$.

E. L. First, C. E. Gounaris, J. Wei, and C. A. Floudas. ZEOMICS. http://helios.princeton.edu/zeomics/, accessed on August 15, 2015. 
K. S. Fisher, K. Searcy, G. T. Rochelle, S. Ziaii, and C. Schubert. Advanced amine solvent formulations and process integration for near-term $\mathrm{CO}_{2}$ capture success. a report submitted to u.s. department of energy, 2007. URL http://www.trimeric.com/ DOE-KPIP-SBIR-Final-021908.pdf.

C. E. Gounaris, C. A. Floudas, and J. Wei. Rational design of shape selective separation and catalysis-I: Concepts and analysis. Chem. Eng. Sci., 61:7933-7948, 2006a. doi: 10.1016/j.ces. 2006.09.012.

C. E. Gounaris, J. Wei, and C. A. Floudas. Rational design of shape selective separation and catalysis-II: Mathematical model and computational studies. Chem. Eng. Sci., 61:7949-7962, 2006b. doi: 10.1016/j.ces.2006.09.011.

C. E. Gounaris, J. Wei, C. A. Floudas, R. Ranjan, and M. Tsapatsis. Rational design of shape selective separations and catalysis: Lattice relaxation and effective aperture size. AIChE J., 56: 611-632, 2009. doi: 10.1002/aic.12016.

M. M. F. Hasan, R. C. Baliban, J. A. Elia, and C. A. Floudas. Modeling, simulation, and optimization of postcombustion $\mathrm{CO}_{2}$ capture for variable feed concentration and flow rate. 1. chemical absorption and membrane processes. Ind. Eng. Chem. Res., 51(48):15642-15664, 2012a.

M. M. F. Hasan, R. C. Baliban, J. A. Elia, and C. A. Floudas. Modeling, simulation, and optimization of postcombustion $\mathrm{CO}_{2}$ capture for variable feed concentration and flow rate. 2. pressure swing adsorption and vacuum swing adsorption processes. Ind. Eng. Chem. Res., 51(48):1566515682, 2012b.

M. M. F. Hasan, E. L. First, and C. A. Floudas. Cost-effective $\mathrm{CO}_{2}$ capture based on in silico screening of zeolites and process optimization. Phys. Chem. Chem. Phys., 15(40):17601-17618, 2013.

M. M. F. Hasan, F. Boukouvala, E. L. First, and C. A. Floudas. Nationwide, regional, and statewide $\mathrm{CO}_{2}$ capture, utilization, and sequestration supply chain network optimization. Ind. Eng. Chem. Res., 53(18):7489-7506, 2014. 
M. M. F. Hasan, E. L. First, F. Boukouvala, and C. A. Floudas. A multi-scale framework for $\mathrm{CO}_{2}$ capture, utilization, and sequestration: CCUS and CCU. Comput. Chem. Eng., 2015. doi: 10.1016/j.compchemeng.2015.04.034.

C. A. Henao and C. T. Maravelias. Surrogate-based process synthesis. Comput. Aided Chem. Eng., 28:1129-1134, 2010.

M. T. Ho, G. W. Allinson, and D. E. Wiley. Reducing the cost of $\mathrm{CO}_{2}$ capture from flue gases using pressure swing adsorption. Ind. Eng. Chem. Res., 47(14):4883-4890, 2008.

D. R. Jones, M. Schonlau, and W. J. Welch. Efficient global optimization of expensive black-box functions. J. Global Optim., 13(4):455-492, 1998.

A. J. Kidnay, W. R. Parrish, and D. G. McCartney. Fundamentals of Natural Gas Processing, 2nd Edition. Taylor \& Francis Group, Boca Raton, FL, USA, 2011.

MCCCS Towhee. MCCCS Towhee. http://towhee.sourceforge.net/, accessed on November 25, 2014.

P. Nowacki. Coal Gasification Processes. Noyes Data Corp., Park Ridge, NJ, USA, 1994.

S. P. Reynolds, A. D. Ebner, and J. A. Ritter. Stripping psa cycles for $\mathrm{CO}_{2}$ recovery from flue gas at high temperature using a hydrotalcite-like adsorbent. Ind. Eng. Chem. Res., 45(12):4278-4294, 2006.

D. M. Ruthven. Principles of adsorption and adsorption processes. Wiley-Interscience, 1984.

D. M. Ruthven, S. Farooq, and K. S. Knaebel. Pressure swing adsorption. VCH Publishers, New York, 1994.

M. Stewart and K. Arnold. Gas Sweetening and Processing Field Mannual. Gulf Professional Publishing, Elsevier, Waltham, MA, USA, 2011.

M. Syed, G. Soreanu, P. Falletta, and M. Béland. Removal of hydrogen sulfide from gas streams using biological processes - a review. Canadian Biosystems Engineering, 48:2.1-2.14, 2006. 
A. T-Raissi. Technoeconomic analysis of area ii hydrogen production - part 1. final report for doe, 2002.

G. P. Towler, H. K. Shethna, B. Cole, and B. Hajdik. Improved absorber-stripper technology for gas sweetening to ultra-low h2s concentrations. In Proceedings: $76^{\text {th }}$ GPA Annual Convention, Tulsa, OK: Gas Processors Association, pages 93-100, 1997.

R. V. S. Uppaluri, P. Linke, and A. C. Kokossis. Synthesis and optimization of gas permeation membrane networks. Ind. Eng. Chem. Res., 43(15):4305-4322, 2004.

P. A. Webley and J. He. Fast solution-adaptive finite volume method for psa/vsa cycle simulation; 1 single step simulation. Comput. Chem. Eng., 23(11-12):1701-1712, 2000.

R. T. Yang. Gas separation by adsorption processes. 1987. 


\section{List of Figures}

1 Flowchart of the multi-scale zeolite screening and process optimization method for $\mathrm{H}_{2} \mathrm{~S}$ separation. . . . . . . . . . . . . . . . . . 32

2 PSA process for $\mathrm{H}_{2} \mathrm{~S}$ separation. . . . . . . . . . . . . . . 33

3 PSA configurations for (a) $\mathrm{CO}_{2}$ adsorptive, and (b) $\mathrm{H}_{2} \mathrm{~S}$ adsorptive processes. . . . 34 


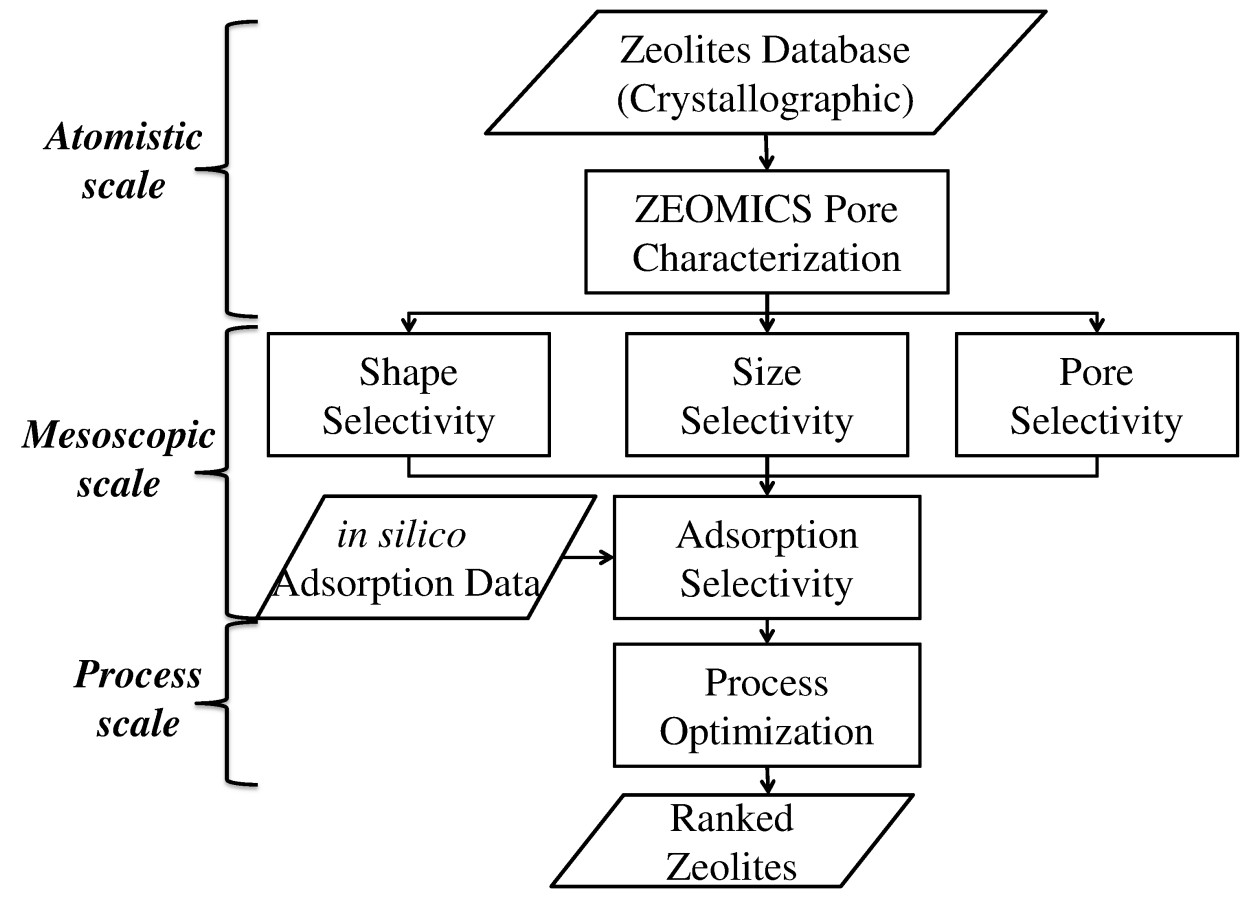

Figure 1: Flowchart of the multi-scale zeolite screening and process optimization method for $\mathrm{H}_{2} \mathrm{~S}$ separation. 

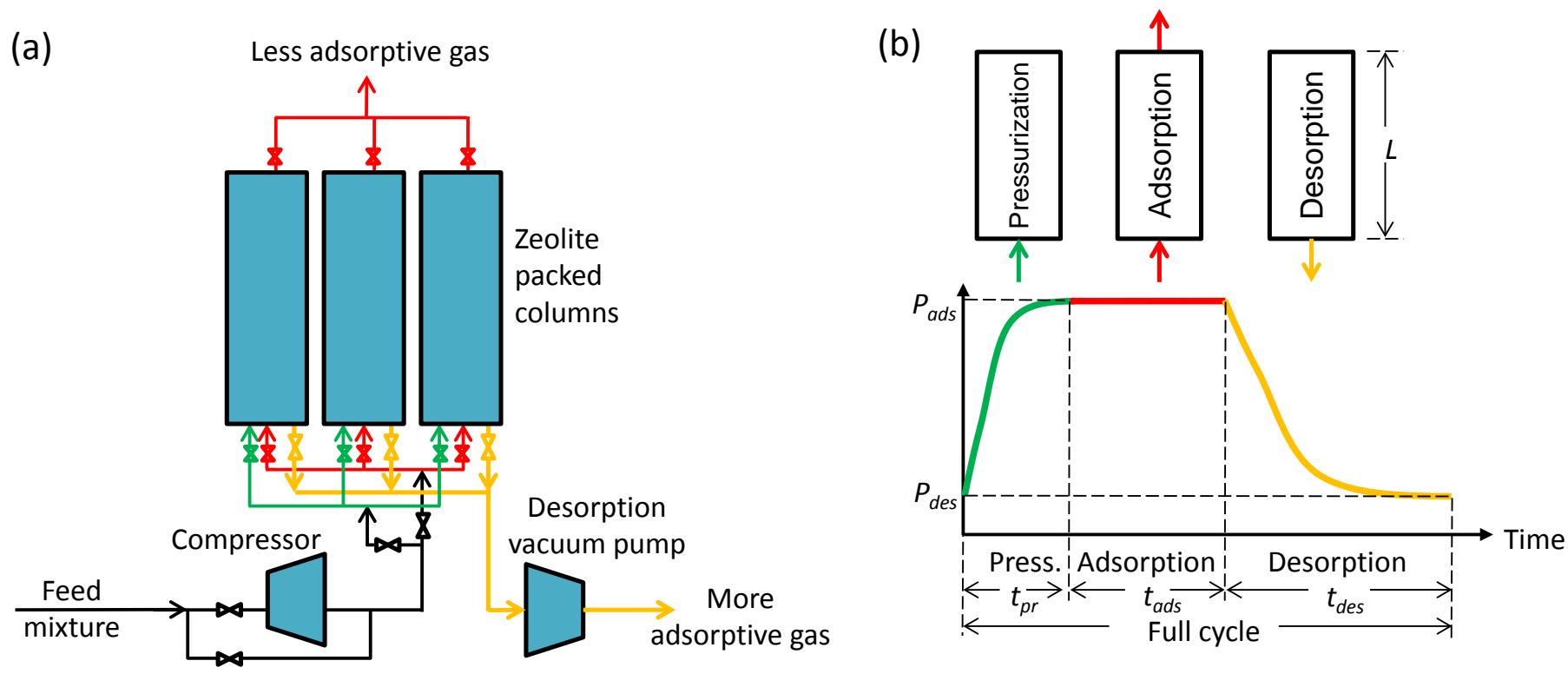

Figure 2: PSA process for $\mathrm{H}_{2} \mathrm{~S}$ separation: (a) process flow diagram with multiple columns, feed compressor and desorption vacuum pump, and (b) pressure profile of the 3-step PSA cycle, which includes (i) pressurization, (ii) adsorption, and (iii) desorption. 
(a) $\mathrm{H}_{2} \mathrm{~S}$ is less Adsorptive

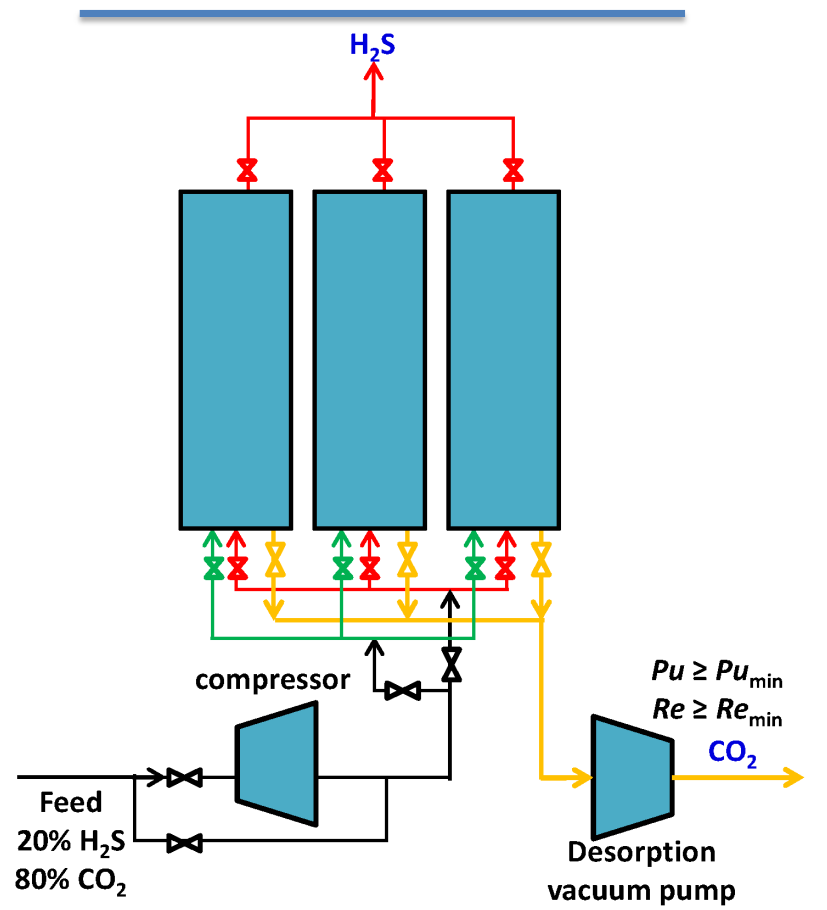

(b) $\mathrm{H}_{2} \mathrm{~S}$ is more adsorptive

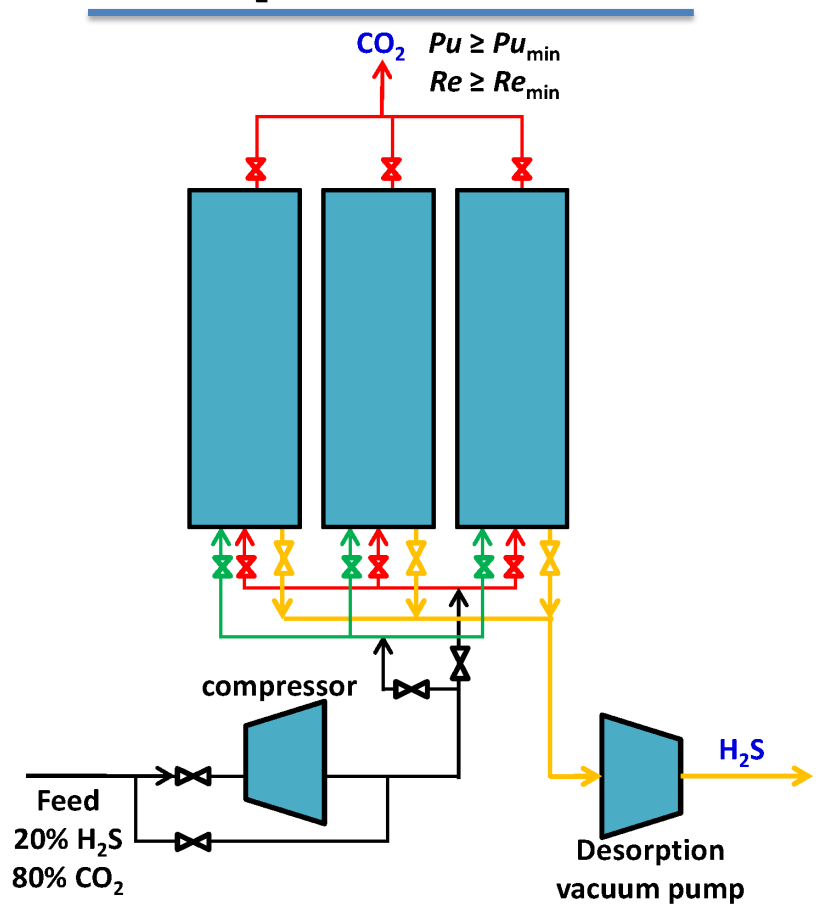

Figure 3: PSA configurations for (a) $\mathrm{CO}_{2}$ adsorptive, and (b) $\mathrm{H}_{2} \mathrm{~S}$ adsorptive processes. 


\section{List of Tables}

1 PSA process model parameters. . . . . . . . . . . . . . . 36

$2 \mathrm{CO}_{2}$-selective zeolites for $\mathrm{CO}_{2} / \mathrm{H}_{2} \mathrm{~S}$ separation, based on shape, size, pore and adsorption selectivities. . . . . . . . . . . . . . . . . . . 37

3 Zeolites for $\mathrm{CO}_{2} / \mathrm{H}_{2} \mathrm{~S}$ separation which shows high shape, size and pore selectivity but reverse adsorption selectivity for $\mathrm{CO}_{2} \ldots \ldots \ldots \ldots$. . . . . . . 38

4 PSA results for the top $\mathrm{CO}_{2}$-selective zeolites for $\mathrm{H}_{2} \mathrm{~S}$ separation from $\mathrm{CO}_{2} / \mathrm{H}_{2} \mathrm{~S}$ mixture. . . . . . . . . . . . . . . . . . . . . . . . . 39

5 Zeolite ranking for $\mathrm{CO}_{2}$ separation from $\mathrm{H}_{2} \mathrm{~S}, \mathrm{CH}_{4}$ and $\mathrm{N}_{2} \ldots \ldots \ldots 40$

$6 \quad$ PSA results for the top $\mathrm{H}_{2} \mathrm{~S}$-selective zeolites for $\mathrm{H}_{2} \mathrm{~S}$ for $\mathrm{CO}_{2} / \mathrm{H}_{2} \mathrm{~S}$ mixture. . . . . 41

$7 \quad \mathrm{H}_{2} \mathrm{~S}$ selective zeolites for $\mathrm{H}_{2} \mathrm{~S} / \mathrm{N}_{2}$ separation, based on shape, size, pore and adsorption selectivities. . . . . . . . . . . . . . . . . . 42

8 Top zeolites for $\mathrm{H}_{2} \mathrm{~S}$ separation from $\mathrm{H}_{2} \mathrm{~S} / \mathrm{N}_{2}$ mixture. . . . . . . . . . . . . . 43

$9 \quad \mathrm{H}_{2} \mathrm{~S}$ selective zeolites for $\mathrm{H}_{2} \mathrm{~S} / \mathrm{CH}_{4}$ separation, based on shape, size, pore and adsorption selectivities. . . . . . . . . . . . . . . . . . . . . 44

10 Cost breakdown results $\ldots \ldots \ldots \ldots \ldots$ 
Table 1: PSA process model parameters.

\begin{tabular}{|c|c|}
\hline Parameter & Description \\
\hline$F$ & feed flow rate \\
\hline$y_{i, f}$ & mole fraction of component $i$ in the feed gas \\
\hline$T_{o}$ & feed temperature \\
\hline$P_{f}$ & feed flow rate \\
\hline$u_{o}$ & feed velocity \\
\hline$T_{a}$ & outside air temperature \\
\hline$y_{i, 0}$ & initial mole fraction of component $i$ in the column \\
\hline$P_{\text {atm }}$ & atmospheric pressure \\
\hline$K_{z}$ & effective heat conductivity \\
\hline$K_{w}$ & thermal heat conductivity of column wall \\
\hline$h_{\text {in }}$ & heat transfer coefficient inside the column \\
\hline$h_{o}$ & heat transfer coefficient for outside the column \\
\hline$C_{p w}$ & specific heat capacity of column wall \\
\hline$C_{p g}$ & specific heat capacity of gas mixture \\
\hline$C_{p a}$ & specific heat capacity of adsorbed gas in solid \\
\hline$C_{p s}$ & specific heat capacity of adsorbent \\
\hline$R$ & gas constant \\
\hline$q_{s}$ & saturation capacity \\
\hline$b_{i}^{o}$ & isotherm parameter for component $i$ ) \\
\hline$D_{M}$ & molecular diffusivity \\
\hline$D_{p}$ & macropore diffusivity, $\left.D_{p}=\frac{D_{M}}{\tau_{p}}\right)$ \\
\hline$D_{L}$ & axial dispersion coefficient defined by the correlation: $D_{L}=0.7 D_{M}+0.5 u_{o} d_{p}$ ) \\
\hline$U C$ & unit operating cost \\
\hline$d_{p}$ & particle diameter \\
\hline$r_{p}$ & particle radius, $\frac{d_{p}}{2}$ ) \\
\hline$k_{p}$ & bed permeability defined by the correlation: $k_{p}=\frac{d_{p}^{2}}{150}\left(\frac{\varepsilon}{1-\varepsilon}\right)^{2}$ \\
\hline$r_{\text {in }}$ & inside radius of the packed column \\
\hline$r_{o}$ & outside radius of the packed column \\
\hline$P u_{\min }$ & specified minimum purity \\
\hline $\operatorname{Re}_{\min }$ & specified minimum recovery \\
\hline$\Delta U_{i}$ & heat of adsorption for component $i$ \\
\hline$\tau_{p}$ & tortuosity factor \\
\hline$\varepsilon_{p}$ & particle porosity \\
\hline$\varepsilon$ & bed porosity \\
\hline$\rho_{w}$ & density of column \\
\hline$\rho_{s}$ & density of solid particle \\
\hline$\mu$ & gas viscosity \\
\hline$\phi$ & annualization factor \\
\hline$\alpha$ & unit capital cost \\
\hline$\beta$ & coefficients of the quadratic surrogate models \\
\hline$\gamma$ & exponent of power cost \\
\hline
\end{tabular}


Table 2: $\mathrm{CO}_{2}$-selective zeolites for $\mathrm{CO}_{2} / \mathrm{H}_{2} \mathrm{~S}$ separation, based on shape, size, pore and adsorption selectivities.

\begin{tabular}{|ccccccc|}
\hline Zeolite & $\begin{array}{c}\text { LCD } \\
(\AA)\end{array}$ & $\begin{array}{c}\text { PLD } \\
(\AA)\end{array}$ & $\begin{array}{c}\text { Shape selectivity } \\
\left(S_{\text {shape }, \mathrm{CO}_{2} / \mathrm{H}_{2} S}\right)\end{array}$ & $\begin{array}{c}\text { Size selectivity } \\
\left(S_{\text {size }, \mathrm{CO}_{2} / \mathrm{H}_{2} S}\right)\end{array}$ & $\begin{array}{c}\text { Pore selectivity } \\
\left(S_{\text {pore }, \mathrm{CO}_{2} / \mathrm{H}_{2} S}\right)\end{array}$ & $\begin{array}{c}\text { Adsorption selectivity } \\
\left(S_{a d s, \mathrm{CO}_{2} / \mathrm{H}_{2} S}\right)\end{array}$ \\
\hline AHT & 4.6 & 3.4 & 0 & 0.396 & 0.4258 & 38849.16 \\
LOS & 7.0 & 3.1 & 0 & 0.5864 & 0.9765 & 2276.41 \\
ABW & 4.1 & 4.1 & 0 & 0 & 0.2836 & 627.46 \\
NSI & 4.8 & 3.4 & 1 & 0.2461 & 0.3365 & 200.77 \\
BIK & 4.8 & 3.6 & 1 & 0 & 0.1283 & 51.97 \\
MON & 4.9 & 3.5 & 1 & 0 & 0.0762 & 50.88 \\
AEN & 5.1 & 3.7 & 1 & 0 & 0.0083 & 29.93 \\
APC & 4.9 & 3.8 & 1 & 0 & 0.1936 & 26.4 \\
YUG & 5.1 & 3.7 & 1 & 0 & 0.006 & 4.74 \\
GME & 7.7 & 7.7 & 0.4688 & 0 & 0.0065 & 2.01 \\
GOO & 5.1 & 3.6 & 1 & 0 & 0.2329 & 1.41 \\
ITW & 5.4 & 3.4 & 0 & 0.1296 & 0.165 & 1.37 \\
RSN & 5.8 & 3.4 & 1 & 0 & 0.0419 & 1.23 \\
PAU & 11.1 & 4.7 & 0.3314 & 0 & 0.0087 & 1.18 \\
SZR & 6.9 & 5.3 & 0.3812 & 0 & 0.0155 & 1.04 \\
& & & & & & \\
\hline
\end{tabular}


Table 3: Zeolites for $\mathrm{CO}_{2} / \mathrm{H}_{2} \mathrm{~S}$ separation which shows high shape, size and pore selectivity but reverse adsorption selectivity for $\mathrm{CO}_{2}$.

Zeolite LCD PLD Shape selectivity Size selectivity Pore selectivity Adsorption selectivity

\begin{tabular}{|c|c|c|c|c|c|c|}
\hline & $(\AA)$ & $(\AA)$ & $\left(\mathrm{S}_{\text {shape }, \mathrm{CO}_{2} / \mathrm{H}_{2} \mathrm{~S}}\right)$ & $\left(\mathrm{S}_{\text {size }, \mathrm{CO}_{2} / \mathrm{H}_{2} \mathrm{~S}}\right)$ & $\left(\mathrm{S}_{\text {pore }, \mathrm{CO}_{2} / \mathrm{H}_{2} \mathrm{~S}}\right)$ & $\left(\mathrm{S}_{a d s, \mathrm{CO}_{2} / \mathrm{H}_{2} S}\right)$ \\
\hline $\mathrm{LOV}$ & 5.8 & 3.4 & 1 & 0.3201 & 0.3352 & 0.95 \\
\hline $\mathrm{AFN}$ & 5.9 & 3.7 & 1 & 0 & 0.0513 & 0.93 \\
\hline $\mathrm{DOH}$ & 8.5 & 3.3 & 0 & 0.732 & 0.8382 & 0.9 \\
\hline CAS & 5.7 & 3.5 & 1 & 0.185 & 0.2141 & 0.81 \\
\hline $\mathrm{AFX}$ & 7.8 & 4.1 & 0.4114 & 0 & 0.0097 & 0.76 \\
\hline MOR & 6.5 & 6.5 & 0.4499 & 0 & 0.0008 & 0.67 \\
\hline DFT & 5.7 & 4.3 & 0.2742 & 0 & 0.0024 & 0.57 \\
\hline LTA & 11.7 & 4.9 & 0 & 0 & 0.0061 & 0.57 \\
\hline EAB & 7.4 & 3.4 & 0 & 0.1258 & 0.2609 & 0.56 \\
\hline VNI & 5.4 & 3.2 & 0 & 0.0286 & 0.1281 & 0.49 \\
\hline NES & 6.6 & 5.7 & 0 & 0 & 0.0189 & 0.43 \\
\hline BRE & 5.9 & 3.5 & 1 & 0.2561 & 0.2645 & 0.42 \\
\hline LTF & 8.1 & 8.1 & 0.6381 & 0 & 0.1184 & 0.41 \\
\hline MFS & 6.0 & 6.0 & 0.2353 & 0 & 0.0412 & 0.41 \\
\hline MAZ & 8.1 & 8.1 & 0.611 & 0 & 0.1817 & 0.37 \\
\hline GIU & 7.0 & 2.9 & 0 & 0.7056 & 0.9127 & 0.32 \\
\hline MEI & 7.5 & 7.5 & 0.3602 & 0 & 0.112 & 0.31 \\
\hline TON & 5.7 & 5.7 & 0 & 0 & 0.265 & 0.31 \\
\hline CGF & 6.4 & 3.5 & 1 & 0.1784 & 0.5212 & 0.28 \\
\hline IWW & 7.2 & 6.9 & 0.6153 & 0 & 0.0469 & 0.28 \\
\hline FRA & 7.3 & 3.3 & 0 & 0.5771 & 0.6507 & 0.26 \\
\hline ESV & 6.9 & 3.7 & 1 & 0 & 0.0124 & 0.22 \\
\hline SOD & 7.0 & 3.2 & 0 & 0.7035 & 0.9216 & 0.21 \\
\hline APD & 5.6 & 3.8 & 1 & 0 & 0.0716 & 0.2 \\
\hline SAT & 7.5 & 3.6 & 1 & 0 & 0.012 & 0.2 \\
\hline $\mathrm{NON}$ & 7.1 & 2.9 & 0 & 0.2442 & 0.96 & 0.18 \\
\hline FAR & 6.7 & 2.7 & 0 & 0.5574 & 0.9149 & 0.13 \\
\hline TOL & 7.0 & 2.6 & 0 & 0.4305 & 0.9141 & 0.1 \\
\hline $\mathrm{SBN}$ & 5.7 & 3.4 & 1 & 0.2701 & 0.2707 & 0.08 \\
\hline $\mathrm{AFG}$ & 7.0 & 2.7 & 0 & 0.0934 & 0.9967 & - \\
\hline ANA & 4.9 & 3.0 & 0 & 0.4387 & 0.99 & - \\
\hline AST & 8.6 & 2.5 & 0 & 0.0182 & 0.9956 & - \\
\hline BCT & 4.4 & 3.2 & 0 & 0.4994 & 0.7834 & - \\
\hline JBW & 3.8 & 3.8 & 1 & 0 & 0.2571 & - \\
\hline LIO & 6.3 & 2.5 & 0 & 0.009 & 0.9997 & - \\
\hline LTN & 10.8 & 2.4 & 0 & 0.009 & 0.9979 & - \\
\hline MAR & 7.0 & 3.0 & 0 & 0.4298 & 0.9904 & - \\
\hline MEP & 6.1 & 2.3 & 0 & 0.0071 & 0.9983 & - \\
\hline MTN & 8.0 & 2.5 & 0 & 0.0155 & 0.9994 & - \\
\hline MVY & 4.4 & 3.1 & 0 & 0.529 & 0.8016 & - \\
\hline RUT & 6.6 & 2.2 & 0 & 38.0005 & 0.9998 & - \\
\hline SGT & 8.4 & 2.7 & 0 & 0.0677 & 0.9901 & - \\
\hline
\end{tabular}


Table 4: PSA results for the top $\mathrm{CO}_{2}$-selective zeolites for $\mathrm{H}_{2} \mathrm{~S}$ separation from $\mathrm{CO}_{2} / \mathrm{H}_{2} \mathrm{~S}$ mixture.

\begin{tabular}{|c|c|c|c|c|c|c|c|c|}
\hline \multirow[b]{2}{*}{ Zeolite } & \multicolumn{2}{|c|}{ Adsorption step } & \multicolumn{2}{|c|}{ Desorption step } & \multirow[b]{2}{*}{$\begin{array}{l}\text { Column } \\
\text { length }(\mathrm{m})\end{array}$} & \multirow[b]{2}{*}{$\begin{array}{c}\mathrm{CO}_{2} \\
\text { purity }(\%)\end{array}$} & \multirow[b]{2}{*}{$\begin{array}{c}\mathrm{CO}_{2} \\
\text { recovery }(\%)\end{array}$} & \multirow[b]{2}{*}{$\begin{array}{c}\text { Cost } \\
(\mathrm{MM} \$)\end{array}$} \\
\hline & $\begin{array}{c}\text { pressure } \\
\text { (bar) }\end{array}$ & $\begin{array}{l}\text { time } \\
(\mathrm{s})\end{array}$ & $\begin{array}{c}\text { pressure } \\
\text { (bar) }\end{array}$ & $\begin{array}{l}\text { time } \\
\text { (s) }\end{array}$ & & & & \\
\hline BIK & 2 & 18.74 & 0.01 & 300 & 1 & 98 & 92 & 3.35 \\
\hline NSI & 1.03 & 15 & 0.01 & 200 & 1 & 98 & 92 & 3.45 \\
\hline AEN & 2.31 & 15.32 & 0.005 & 231 & 1 & 99 & 90 & 3.57 \\
\hline LOS & 3.13 & 8.34 & 0.01 & 121 & 1 & 98 & 90 & 3.67 \\
\hline
\end{tabular}


Table 5: Zeolite ranking for $\mathrm{CO}_{2}$ separation from $\mathrm{H}_{2} \mathrm{~S}, \mathrm{CH}_{4}$ and $\mathrm{N}_{2}$.

\begin{tabular}{|cccc|}
\hline Zeolite & $\begin{array}{c}\mathrm{H}_{2} \mathrm{~S} \text { removal } \\
\mathrm{CO}_{2} / \mathrm{H}_{2} \mathrm{~S}\end{array}$ & $\begin{array}{c}\text { Natural gas purification } \\
\mathrm{CO}_{2} / \mathrm{CH}_{4}\end{array}$ & $\begin{array}{c}\text { Carbon capture } \\
\mathrm{CO}_{2} / \mathrm{N}_{2}\end{array}$ \\
\hline BIK & 1 & 5 & $>26$ \\
NSI & 2 & 9 & $>26$ \\
AEN & 3 & 2 & $>26$ \\
LOS & 4 & $>10$ & 24 \\
ABW & 7 & 8 & 4 \\
& & & \\
\hline
\end{tabular}


Table 6: PSA results for the top $\mathrm{H}_{2} \mathrm{~S}$-selective zeolites for $\mathrm{H}_{2} \mathrm{~S}$ for $\mathrm{CO}_{2} / \mathrm{H}_{2} \mathrm{~S}$ mixture.

\begin{tabular}{|c|c|c|c|c|c|c|c|c|}
\hline \multirow[b]{2}{*}{ Zeolite } & \multicolumn{2}{|c|}{ Adsorption step } & \multicolumn{2}{|c|}{ Desorption step } & \multirow[b]{2}{*}{$\begin{array}{l}\text { Column } \\
\text { length }(\mathrm{m})\end{array}$} & \multirow[b]{2}{*}{$\begin{array}{c}\mathrm{CO}_{2} \\
\text { purity }(\%)\end{array}$} & \multirow[b]{2}{*}{$\begin{array}{c}\mathrm{CO}_{2} \\
\text { recovery }(\%)\end{array}$} & \multirow[b]{2}{*}{$\begin{array}{c}\text { Cost } \\
(\mathrm{MM} \$)\end{array}$} \\
\hline & $\begin{array}{c}\text { pressure } \\
\text { (bar) }\end{array}$ & $\begin{array}{l}\text { time } \\
(\mathrm{s})\end{array}$ & $\begin{array}{l}\text { pressure } \\
\text { (bar) }\end{array}$ & $\begin{array}{l}\text { time } \\
\text { (s) }\end{array}$ & & & & \\
\hline TOL & 12.23 & 72.96 & 0.04 & 272.73 & 2.00 & 98 & 93 & 2.11 \\
\hline TON & 14.62 & 90.08 & 0.02 & 267.78 & 1.10 & 98 & 90 & 2.23 \\
\hline MOR & 19.21 & 69.54 & 0.03 & 295.00 & 1.95 & 98 & 91 & 2.55 \\
\hline
\end{tabular}


Table 7: $\mathrm{H}_{2} \mathrm{~S}$ selective zeolites for $\mathrm{H}_{2} \mathrm{~S} / \mathrm{N}_{2}$ separation, based on shape, size, pore and adsorption selectivities.

\begin{tabular}{|ccccccc|}
\hline Zeolite & $\begin{array}{c}\text { LCD } \\
(\AA)\end{array}$ & $\begin{array}{c}\text { PLD } \\
(\AA)\end{array}$ & $\begin{array}{c}\text { Shape selectivity } \\
\left(S_{\text {shape } H_{2} S / N_{2}}\right)\end{array}$ & $\begin{array}{c}\text { Size selectivity } \\
\left(S_{\text {size }, H_{2} S / N_{2}}\right)\end{array}$ & $\begin{array}{c}\text { Pore selectivity } \\
\left(S_{\text {pore }, H_{2} S / N_{2}}\right)\end{array}$ & $\begin{array}{c}\text { Adsorption selectivity } \\
\left(S_{a d s, H_{2} S / N_{2}}\right)\end{array}$ \\
\hline AWO & 5.8 & 4.3 & 0 & 0.22 & 0.22 & 227.8 \\
APD & 5.6 & 3.8 & 0 & 1.00 & 0.12 & 170.4 \\
DFT & 5.7 & 4.3 & 0 & 0.27 & 0.00 & 122.0 \\
ATV & 5.4 & 4.1 & 0 & 0 & 0.22 & 118.0 \\
SBN & 5.7 & 3.4 & 0.27 & 1.00 & 0.28 & 108.7 \\
TOL & 7.0 & 2.6 & 0.84 & 0 & 0.96 & 89.79 \\
ZON & 6.5 & 4.0 & 0 & 0.17 & 0.06 & 88.89 \\
SOD & 7.0 & 3.2 & 0.94 & 1.00 & 0.94 & 81.77 \\
BRE & 5.9 & 3.5 & 0.26 & 1.00 & 0.27 & 77.07 \\
MER & 7.3 & 4.8 & 0 & 0.20 & 0 & 73.83 \\
GIU & 7.0 & 2.9 & 0.90 & 0 & 0.95 & 70.18 \\
ATN & 6.6 & 4.7 & 0 & 0.25 & 0.16 & 69.63 \\
MOR & 6.5 & 6.5 & 0 & 0.45 & 0.01 & 68.20 \\
ESV & 6.9 & 3.7 & 0 & 1.00 & 0.03 & 67.13 \\
CGF & 6.4 & 3.5 & 0.18 & 1.00 & 0.62 & 66.85 \\
FRA & 7.3 & 3.3 & 0.62 & 1.00 & 0.67 & 66.52 \\
TON & 5.7 & 5.7 & 0 & 0.30 & 0.38 & 64.99 \\
THO & 5.8 & 4.1 & 0 & 0.18 & 0.01 & 64.32 \\
LTF & 8.1 & 8.1 & 0 & 0.70 & 0.14 & 60.06 \\
MAZ & 8.1 & 8.1 & 0 & 0.63 & 0.20 & 58.39 \\
UOS & 6.5 & 4.2 & 0 & 0.10 & 0.10 & 58.33 \\
MFS & 6.0 & 6.0 & 0 & 0.25 & 0.05 & 57.90 \\
EON & 7.3 & 7.3 & 0 & 0.48 & 0.17 & 55.69 \\
ATO & 6.1 & 6.1 & 0 & 0 & 0.12 & 55.20 \\
LOV & 5.8 & 3.4 & 0.32 & 1.00 & 0.36 & 54.67 \\
OFF & 7.3 & 7.3 & 0 & 0.45 & 0.02 & 54.43 \\
SAT & 7.5 & 3.6 & 0 & 1.00 & 0.05 & 53.36 \\
FAR & 6.7 & 2.7 & 0.90 & 0 & 0.95 & 52.83 \\
NON & 7.1 & 2.9 & 0.65 & 0 & 0.98 & 51.65 \\
LEV & 7.7 & 3.4 & 0 & 1.00 & 0.13 & 50.14 \\
IHW & 6.2 & 4.0 & 0 & 0.52 & 0.04 & \\
& & & & & & \\
\hline
\end{tabular}


Table 8: Top zeolites for $\mathrm{H}_{2} \mathrm{~S}$ separation from $\mathrm{H}_{2} \mathrm{~S} / \mathrm{N}_{2}$ mixture.

\begin{tabular}{|c|c|c|c|c|c|c|c|c|}
\hline \multirow[b]{2}{*}{ Zeolite } & \multicolumn{2}{|c|}{ Adsorption step } & \multicolumn{2}{|c|}{ Desorption step } & \multirow[b]{2}{*}{$\begin{array}{l}\text { Column } \\
\text { length }(\mathrm{m})\end{array}$} & \multirow[b]{2}{*}{$\begin{array}{c}\mathrm{N}_{2} \\
\text { purity }(\%)\end{array}$} & \multirow[b]{2}{*}{$\begin{array}{c}\mathrm{N}_{2} \\
\text { recovery (\%) }\end{array}$} & \multirow[b]{2}{*}{$\begin{array}{c}\text { Cost } \\
(\mathrm{MM} \$)\end{array}$} \\
\hline & $\begin{array}{c}\text { pressure } \\
\text { (bar) }\end{array}$ & $\begin{array}{l}\text { time } \\
(\mathrm{s})\end{array}$ & $\begin{array}{c}\text { pressure } \\
\text { (bar) }\end{array}$ & $\begin{array}{l}\text { time } \\
(\mathrm{s})\end{array}$ & & & & \\
\hline ATV & 5.00 & 50.00 & 0.01 & 113.46 & 1.0 & 99 & 94 & 1.65 \\
\hline AWO & 4.40 & 49.65 & 0.03 & 137.00 & 1.0 & 99 & 93 & 1.49 \\
\hline MER & 5.00 & 50.00 & 0.01 & 113.46 & 1.0 & 99 & 92 & 1.66 \\
\hline BRE & 4.48 & 46.15 & 0.04 & 147.00 & 1.0 & 99 & 90 & 1.50 \\
\hline
\end{tabular}


Table 9: $\mathrm{H}_{2} \mathrm{~S}$ selective zeolites for $\mathrm{H}_{2} \mathrm{~S} / \mathrm{CH}_{4}$ separation, based on shape, size, pore and adsorption selectivities.

\begin{tabular}{|ccccccc|}
\hline Zeolite & $\begin{array}{c}\text { LCD } \\
(\AA)\end{array}$ & $\begin{array}{c}\text { PLD } \\
(\AA)\end{array}$ & $\begin{array}{c}\text { Shape selectivity } \\
\left(S_{\left.\text {shape } H_{2} S / C H_{4}\right)}\right)\end{array}$ & $\begin{array}{c}\text { Size selectivity } \\
\left(S_{\text {size, } H_{2} S / C H_{4}}\right)\end{array}$ & $\begin{array}{c}\text { Pore selectivity } \\
\left(S_{\text {pore }, H_{2} S / C H_{4}}\right)\end{array}$ & $\begin{array}{c}\text { Adsorption selectivity } \\
\left(S_{\text {ads }, H_{2} S / C H_{4}}\right)\end{array}$ \\
\hline AWO & 5.8 & 4.3 & 0 & 0 & 0.1095 & 32.9 \\
SBN & 5.7 & 3.4 & 0.2701 & 0 & 0.2736 & 19.71 \\
MER & 7.3 & 4.8 & 0 & 0.3879 & 0 & 14.17 \\
LOV & 5.8 & 3.4 & 0.3201 & 0 & 0.3188 & 13.59 \\
RWR & 5.1 & 3.8 & 0 & 1 & 0 & 13.01 \\
DAC & 5.8 & 4.8 & 0 & 0.4487 & 0 & 12.71 \\
JRY & 5.2 & 3.9 & 0 & 1 & 0.0046 & 11.75 \\
GOO & 5.1 & 3.6 & 0 & 0 & 0.1838 & 11.53 \\
GIS & 5.6 & 3.9 & 0 & 1 & 0 & 11.3 \\
ATN & 6.6 & 4.7 & 0 & 0 & 0.1272 & 11.04 \\
SIV & 6.0 & 4.4 & 0 & 0.5369 & 0.0016 & 10.14 \\
SOF & 4.8 & 4.7 & 0 & 0.3975 & 0.0001 & 10.1 \\
ITW & 5.4 & 3.4 & 0.1296 & 0 & 0.1472 & \\
& & & & & & \\
\hline
\end{tabular}


Table 10: Cost breakdown results

\begin{tabular}{|c|c|c|c|c|c|}
\hline Zeolite & $\begin{array}{l}\text { Investment cost } \\
(\$ / y r)\end{array}$ & $\begin{array}{c}\text { Operating cost } \\
(\$ / y r)\end{array}$ & column & $\begin{array}{c}\text { Duty of feed } \\
\text { compressor }(\mathrm{kW} / \mathrm{kmol})\end{array}$ & $\begin{array}{l}\text { Duty of vacuum } \\
\text { pump }(\mathrm{kW} / \mathrm{kmol})\end{array}$ \\
\hline & & \multicolumn{2}{|c|}{$\mathrm{H}_{2} \mathrm{~S}_{\mathrm{CO}_{2}}$ separation } & & \\
\hline TOL & $1,281,884$ & 826,668 & 1 & 12,098 & 1,628 \\
\hline TON & $1,341,497$ & 888,051 & 1 & 13,337 & 1,569 \\
\hline \multirow[t]{2}{*}{ MOR } & $1,509,647$ & $1,036,792$ & 1 & 15,359 & 2,162 \\
\hline & & \multicolumn{2}{|c|}{$\mathrm{H}_{2} \mathrm{~S} / \mathrm{N}_{2}$ separation } & & \\
\hline ATV & $1,052,258$ & 599,331 & $\overline{1}$ & 6,759 & 2,022 \\
\hline AWO & 963,808 & 529,332 & 1 & 6,102 & 1,388 \\
\hline MER & $1,054,996$ & 601,461 & 1 & 6,760 & 2,061 \\
\hline \multirow[t]{2}{*}{ BRE } & 969,712 & 534,017 & 1 & 6,193 & 1,366 \\
\hline & & \multicolumn{2}{|c|}{$\underline{\mathrm{H}_{2} \mathrm{~S} / \mathrm{CH}_{4} \text { separation }}$} & & \\
\hline MER & $1,094,053$ & 632,809 & 1 & 6,268 & 3,039 \\
\hline
\end{tabular}

